NBER WORKING PAPER SERIES

\title{
INCOME-CONTINGENT LOANS AS AN UNEMPLOYMENT BENEFIT
}

\author{
Haaris Mateen $\mathrm{P}$ \\ Joseph E. Stiglitz $\mathrm{P}$ \\ Jungyoll Yun \\ Working Paper 29198 \\ http://www.nber.org/papers/w29198 \\ NATIONAL BUREAU OF ECONOMIC RESEARCH \\ 1050 Massachusetts Avenue \\ Cambridge, MA 02138 \\ August 2021
}

All authors contributed equally to this manuscript. The order of author names is randomized via the AEA Randomization Tool. The authors are indebted to the Fulbright Foundation, INET, and the Roosevelt Institute for financial support, to Matthieu Teachout and Nahyun Lim for research assistance, and to article editors Debarati Ghosh and Andrea Gurwitt. The views expressed herein are those of the authors and do not necessarily reflect the views of the National Bureau of Economic Research.

NBER working papers are circulated for discussion and comment purposes. They have not been peer-reviewed or been subject to the review by the NBER Board of Directors that accompanies official NBER publications.

(C) 2021 by Haaris Mateen (r) Joseph E. Stiglitz () and Jungyoll Yun. All rights reserved. Short sections of text, not to exceed two paragraphs, may be quoted without explicit permission provided that full credit, including (C) notice, is given to the source. 
Income-Contingent Loans As an Unemployment Benefit

Haaris Mateen (r) Joseph E. Stiglitz (r) Jungyoll Yun

NBER Working Paper No. 29198

August 2021

JEL No. D15,H53,H81,I38,J64,J65

\begin{abstract}
Imperfections in risk and capital markets imply that individuals who lose jobs suffer from imperfect smoothing of consumption across states and times. Compared to the first best, there will be too little search. Optimal unemployment programs, which balance the marginal benefit of consumption smoothing vs. the marginal cost of the insurance externality, increase welfare and may even increase GDP. Our analytical results suggest that welfare is higher if the unemployment benefits program includes income-contingent unemployment loans (ICL), where the amount repaid depends on the individual's future income. Such loans can be financed by a risk premium imposed on the unemployed who avail themselves of the loans, and partially substitute for unemployment insurance (UI) benefits. Optimal unemployment benefits programs (UB) with ICL do a better job of smoothing consumption across states and time, and in particular total benefits when unemployed increase. We analyze how changes in key parameters, such as the degree of risk aversion and the nature of post-employment work, affect the design of the optimal UB program and the magnitude of the incremental benefits from including income-contingent loans.
\end{abstract}

Haaris Mateen

Columbia University

hm2692@columbia.edu

Joseph E. Stiglitz

Uris Hall, Columbia University

3022 Broadway, Room 212

New York, NY 10027

and NBER

jes322@columbia.edu
Jungyoll Yun

Department of Economics, Ewha University

Seoul

Korea

jyyun@ewha.ac.kr 


\section{Introduction}

Unemployment shocks lead to disparities in consumption both across time and states ${ }^{2}$. Imperfections in risk and capital markets imply that there is imperfect intertemporal and interstate consumption smoothing, leading to potentially large welfare losses. Unemployment insurance (UI) smooths these disparities. But like any insurance, UI introduces distortions- into search intensity and job acceptance. Concerns over these effects have been highlighted in recent controversies surrounding the expansion of $\mathrm{UI}$ during the pandemic. ${ }^{3}$ Optimal unemployment insurance balances at the margin the benefits of consumption smoothing with the adverse effects on search.

Once one embeds $\mathrm{UI}$ in a simple welfare framework with risk-averse individuals, it becomes clear that in the absence of UI, there may be (compared to the first best) too little search: search is a productive but risky activity, and without insurance, individuals may undertake too little of it. We establish within a general analytic framework not dependent on restrictive parameterizations that some UI always leads to an increase in GDP, but not surprisingly, high levels of UI can decrease GDP. ${ }^{4}$ Optimal UI may, of course, entail lower or higher GDP than no UI: the objective of economic policy is not the maximization of GDP, but of welfare.

A focus on $\mathrm{UI}$ as an instrument for consumption smoothing naturally leads to the question: Are there ways of enhancing smoothing? This paper analyzes an efficient system of income support

\footnotetext{
${ }^{2}$ States of nature, in this context, refer to whether the individual loses a job in the first period, whether he quickly gets a job at the same wage or receives a wage offer less than his previous wage, and if so what that wage offer is, and, should he decide not to accept the offer, the wage offers he receives in the second period, given a particular level of search effort. In a multi-period model, the states would similarly describe the whole history of wage offers contingent on search effort. It should be clear that the requisite number of Arrow-Debreu securities, if there were a security for every state of nature (as required if we are to guarantee Pareto efficiency), is enormous.

${ }^{3}$ Interestingly, recent careful studies of the potential adverse effects even of UI payments in excess of wages prior to losing one's job have shown them to be not as significant as had been feared. See Marinescu et al (2020) and Petrosky-Nadeau and Valletta (2020). The recent increases in UI during the pandemic has provided a natural experiment within which to better assess these effects. Ganong et al (2021a, 2021b) document very small search distortions from the expanded UI and causally estimate the disincentive effect to be small even after vaccines are widely available in April 2021.

${ }^{4}$ Early studies of the negative income tax suggested that one of the benefits was that it enabled individuals to search more and get a better job (Kershaw and Skidmore, 1974).
} 
for the unemployed, introducing a new instrument, income-contingent loans (ICL), loans the repayment of which are contingent on individual's later income.

We refer to the combination of standard unemployment insurance (UI) and income-contingent loans (ICL) as the unemployment benefits (UB) package. We show that the optimal UB package always includes income-contingent loans, even if there is the possibility that individuals cannot (or in an optimal scheme would not) repay the loan. Such a package may even increase GDP as search incidence-the number of individuals engaging in search to find a more productive job increases, and these individuals may find a job in which they are more productive than they otherwise would be. A UB program with an ICL entails more consumption smoothing, with a lower level of UI.

In the absence of loans, the UI benefit plays dual roles of improving interstate and intertemporal consumption smoothing. Because insurance distorts search incentives and entails deadweight losses, with optimal insurance, UI will be limited, implying incomplete intertemporal and interstate smoothing. ${ }^{5}$ Unemployment loans avoid some of the welfare losses associated with UI. For those individuals who experience a few short spells of unemployment, the loss of lifetime income from a bout or two of unemployment is relatively small; for these individuals the welfare loss of unemployment arises totally from capital market imperfections that constrain intertemporal consumption smoothing. ${ }^{6}$ Some individuals, however, have numerous or extended episodes of unemployment, with severe implications for

\footnotetext{
${ }^{5}$ A curious aspect of America's unemployment insurance scheme is that it only covers small risks. A basic principle of insurance with moral hazard is that individuals should self-insure for small risks. Insurance should be provided against large risks. If unemployment risks were small, were the UI benefit converted into a loan, default risk would be low and welfare would be increased, since the welfare loss from the moral hazard risk would be decreased (or indeed, eliminated.) See Stiglitz and Yun (2005).

${ }^{6}$ Some macro-economists have tried to argue that the cost of business fluctuations is small (Lucas (1987)), using models where there are perfect capital markets, and ignoring the differential effects of business cycles on different individuals. Were those assumptions correct, the conclusions might be correct, but then economic downturns would not be the subject of such concern among the body politic. Outside the representative agent model, some individuals face large unemployment shocks (i.e. not just a cutback in hours worked); and without perfect capital markets, individuals who face a significant unemployment shock can't smooth their consumption over time.
} 
their lifetime income. ${ }^{7}$ The problem is that potential creditors don't know which individuals will confront such significant lifetime losses and they can't tell whether these extended episodes are a result of bad luck or lack of effort. Individuals too can't see perfectly into the future, and so can't be sure about future employment prospects. If they could, there would be no difficulties smoothing consumption, over an admittedly constrained lifetime budget set. But if the individual were to limit his borrowing to reflect the worst possible contingency, there would be little lifetime smoothing-far less than is socially desirable. Moreover, if individuals are burdened with loans that are not income-contingent and experience a long period of unemployment, what they have to consume after servicing the loans in periods of extended unemployment would be small. Rather than improving consumption smoothing, unemployment loans could have worsened it. Income-contingent loans are thus desirable because they enhance consumption smoothing compared to $U I$ and compared to noncontingent loans.

The loss of welfare from the absence of perfect risk and capital markets can be large when individuals face large shocks to their income and when unemployment occurs early in life, before individuals have had a chance to build up their savings. ${ }^{8} 9$ Income-contingent loans, recognizing this, design debt forgiveness (when the individual's lifetime income is low, for instance because of extended unemployment, the failure to get a good job even after searching) to enhance consumption smoothing.

\footnotetext{
7 In the aftermath of the 2008 financial crisis, an increasing fraction of those unemployed were long term. In the US, in 2015, 19 percent of the unemployed were long term (defined as unemployed for more than a year); in the European Union (28 countries), 49 percent. Source: OECD Labor Force Statistics, 2016

${ }^{8}$ Of course, because of time irreversibility, the fact that individuals early on in life don't know what their future income will be means that there can't be perfect intertemporal smoothing. At best, consumption early in life could be equal to the expected value of consumption later in life. (With risk aversion, intertemporal smoothing entails $U^{\prime}\left(C_{0}\right)=E U^{\prime}\left(C_{1}\right)$, where, in the obvious notation, $C_{i}$ is consumption in period $i$, and lifetime utility is additive, i.e. $W$ $=\Sigma U\left(C_{i}\right)$.)

${ }^{9}$ Moreover, with social security taking on such an important role in the provision of retirement income for individuals in the bottom half of the income distribution, these individuals can't draw upon retirement savings to help smooth out their consumption. Governments have typically imposed restraints on individuals using their future retirement income (especially social security) as collateral against borrowing, even in the case when individuals are unemployed, out of worry that such borrowing risks individuals having insufficient income in their retirement.
} 
Moreover, because search is risky, the availability of such loans enhances the ability and incentives of those who receive a low-wage offer the first period to turn it down and search for a better job. Thus, a well-designed unemployment program with ICL not only reduces intertemporal and interstate consumption differentials, but also improves overall search efficiency, thereby decreasing the welfare loss associated with UI, and in some cases, even increasing GDP.

Thus, our paper calls attention to a particular aspect of imperfections of risk markets, the absence of insurance for "search risk." ${ }^{10}$ We characterize the optimal UB package, the appropriate mix between unemployment insurance and income-contingent loans, and show how the package and its relative performance compared to the traditional UI vary with various factors.

Because there are more market failures and more instruments than those on which traditional analyses of unemployment have focused, it is important to construct a model that is sufficiently general to incorporate (a) all the market failures we have described; (b) all the effects (intertemporal as well as interstate consumption smoothing; search incidence as well as search effort); and (c) all the instruments (income-contingent loans as well as UI, with the parameters, e.g. the amount of loan forgiveness, themselves endogenous). The challenge is to do so while keeping the analysis tractable, and without relying on excessively constraining parameterizations, which limit confidence in the generality of any results obtained. ${ }^{11}$ Indeed, by using a more general formulation, we are able to establish that some of the standard

\footnotetext{
10 The "search risk" referred in this paper includes the risk associated with the variability of reemployment wages, not just the duration risk of a particular unemployment episode. The latter risk has been dealt with by a large literature, including Shavell-Weiss (1979), Hopenhayn-Nicolini (1997), Shimer-Werning (2008)), and Bailey (1978). ${ }^{11}$ In particular, some of the literature in this area has employed particular utility functions, which have particular implications for, e.g. the effect of changes in wealth on willingness to bear risks, the implications of which have, in other contexts (e.g. changes in portfolios as wealth changes) been rejected. Other papers make particular assumptions concerning how job opportunities change over time. The role of such assumptions in the analysis will become clearer after the development of our model. The corresponding disadvantage of our approach is that it is limited to a two-period analysis. As always, there are trade-offs in modelling.
} 
comparative statics propositions concerning UI are of more limited validity than has been generally assumed. ${ }^{12}$

This paper is organized as follows: Section II relates our result to the literature; Section III presents the basic model, and describes the two "benchmarks," the equilibrium with no insurance and the first best situation; Section IV analyzes the effects of unemployment insurance, not just on welfare but on GDP; Section V then introduces ICL, demonstrating their desirability as part of an optimal UB program, describing the optimal design of UB programs, and analyzing some of the determinants of the extent of reliance on ICL within the UB package; Section VI addresses the financing of UI and ICL; Section VII extends the analysis to incorporate simultaneously search incidence and effort; while section VIII clarifies the separate roles played by risk aversion and intertemporal substitutability in the design of UB programs, emphasizing the importance of ICL in the context of limited intertemporal substitutabilty.

\section{Related Literature}

This paper combines insights from two literatures, the small literature on income-contingent loans and the much larger one on $\mathrm{UI}$ and search. ${ }^{13}$ In other contexts, e.g. the financing of higher education, income-contingent loans have been shown to increase welfare. ${ }^{14}$

A large literature including Bailey (1978), Shavell-Weiss (1979), Feldstein and Poterba (1984), Hopenhayn-Nicolini (1997) and Shimer-Werning (2008), point out that unemployment insurance introduces search distortions, discouraging individual's accepting a job (they have too high of a reservation wage), or from exerting effort in search. ${ }^{15}$ These costs have to set against

\footnotetext{
${ }^{12}$ For instance, as we will see, while an increase in risk aversion increases the benefits of unemployment insurance, it may also affect the (marginal) deadweight loss associated with the tax externality.

${ }^{13}$ This latter literature is so vast that we touch on only a selected number of papers that are most closely related to the theoretical insights of this paper.

${ }^{14}$ For a discussion of the variety of experiences with income-contingent loans, see Chapman et al (2014). For theoretical analyses, see Stiglitz (2014) and Stiglitz and Yun (2014).

${ }^{15}$ That literature can be viewed as a special application of the general theory of moral hazard, where the provision of insurance affects efforts devoted to avoiding the insured against event. See, for instance, Arrow (1963) and Arnott and Stiglitz $(1988,1990)$.
} 
the benefit, from improved interstate and intertemporal smoothing. ${ }^{16}$ A series of papers has, moreover, recognized the importance of liquidity constraints, insufficient wealth and insufficient access to capital markets for smoothing consumption over time and financing search. ${ }^{17}$ Flemming (1978) and Hansen-Imrohoroglu (1992) observe that it is the lack of liquidity, rather than a lack of insurance, that an unemployed worker suffers the most from. Chetty (2008) and Landais (2014) attempt empirically to ascertain the relative importance of effects arising from UI's reducing liquidity constraints, and those associated with the moral hazard to which it gives rise, discouraging search, finding that the liquidity effect dominates. ${ }^{18}$ In these papers liquidity constraints induce seemingly excessive search, arising from the fear of not getting a job, inducing individuals to accept jobs earlier than they otherwise would - lower reservation wages, thereby reducing search incidence - and possibly searching more intensively than they otherwise would. ${ }^{19}$

Shimer-Werning (2008) is perhaps the closest in spirit to the analysis presented here. They analyze search in a model where individuals face borrowing constraints, focusing on both interstate and intertemporal smoothing. Our analysis differs from theirs in several ways. Most importantly, while the focus of Shimer-Werning is on the implications of borrowing limits on the optimal time pattern of UI benefits ${ }^{20}$, the focus of our paper is on whether government

\footnotetext{
${ }^{16}$ Gruber (1997) showed empirically that unemployment insurance helped workers smooth their consumption while unemployed.

${ }^{17}$ There is, in fact, a large literature explaining these market imperfections. Stiglitz-Weiss (1981) provided the foundations for limitations on borrowing (credit rationing), based on asymmetric information, and Zeldes (1989) and Jappelli-Pistferri (2010), among others, verified its importance in household decision making.

${ }^{18}$ Chetty (2008) goes so far as to argue that "The optimal UI problem warrants analysis only when there are liquidity effects." While Stiglitz and Yun (2005) had previously shown that to be the case for small unemployment episodes, it is not true more generally, as this paper establishes. There is still a value to interstate consumption smoothing, limitations on interstate smoothing impose limitations on intertemporal smoothing, and both affect search incidence and intensity.

${ }^{19}$ As in much of the literature analyzing effects of risk on behavior (e.g. dating back to Rothschild-Stiglitz, 1970, 1971) there can be ambiguous effects. Without unemployment insurance and no fall back income, individuals may expend enormous efforts to avoid the worst contingency-not having a job. Additional search is a substitute for insurance. On the other hand, if individuals have a good fallback, then search can be viewed as a risky investment, and the greater the risk associated with an investment, the less the individual invests.

The model of the last section of the paper introduces both search incidence and effort simultaneously. .

${ }^{20}$ The borrowing constraint they refer to as the natural borrowing limit that the individual cannot borrow so much that he defaults in any state of nature (any contingency). Of course, most lending entails some probability of
} 
itself should offer loans, and if so, what should the loan program look like. The difference in questions leads naturally to differences in modelling. In their model, as is standard in much of the literature, ${ }^{21}$ the quality of job offers does not change over time. ${ }^{22}$ Here, we show the impacts on both UI and ICL loans of changing job prospects. ${ }^{23} 24$

Much of the earlier literature weighed the marginal consumption-smoothing benefits against the deadweight loss associated with the distortions in search, with the magnitude of the latter captured in search elasticities. While the resulting formulations were useful in assessing whether UI benefits were excessive or too small, they were theoretically unsatisfactory: Search elasticities themselves need to be derived from the primitives of the model, the utility functions and the probability distribution of offers, variables that themselves affect the welfare gains

default, one of the reasons that almost all loans carry an interest rate substantially in excess of the T-bill rate, especially the case for household loans. In any case, government can offer loans that go beyond that amount. ${ }^{21}$ And in particular in models with Poisson arrivals of job offers.

22 In this, they follow a long line of models, including Hopenhayn-Nicolini (1997) and Shavell-Weiss (1979) characterizing the optimal profile of UI benefits over an unemployment episode where the distribution of job offers remains constant over time. The main defense of this assumption is that it greatly simplifies the analysis and allows the use of modelling techniques that yield tractable results, but for reasons set forth below, it clearly does not describe actual market situations.

${ }^{23}$ There are many reasons that the (subjective) probability distribution of wage offers change over time: On the one hand, there can be stigma effects-where potential employers think that those who are unemployed for a long time are lower quality, and there can be depreciation of human capital (Pavoni 2009); while on the other hand, individuals may become more proficient in search over time. Moreover, in the presence of heterogenous firms, the individual will try the best prospects first, leaving the poorer prospects for later; on the other hand, particularly in our model, the initial distribution represents the distribution of offers with no job search; the second period offers occur after job search, and there should be some presumption that the latter is better than the former. More generally, the cumulative information resulting from job search will inevitably change posterior distributions about future job prospects, and even if the prior distribution accurately reflected the actual distribution, but the individual is uncertain about the key parameters of the distribution, the randomness of the first period draw will lead to revisions in beliefs about those parameters.

Time-varying patterns of wage offers obviously have important implications for the optimal time profile of UI benefits. The analysis of this paper makes clear, however, that the dependence of observed wages on the duration of unemployment does not necessarily reflect just changes in opportunity sets (the probability distribution of offers). Preferences/risk aversion and liquidity constraints change over time. Michelacci-Ruffo (2015) show, for instance, that the optimal UI for older workers for whom the moral hazard effects (they argue) of search are greater and relatively large amount of assets should be lower than that for younger workers.

${ }^{24}$ Another paper that, like ours, emphasizes the efficiency benefits of $\mathrm{UI}$ in a world with incomplete risk markets, though through a quite different mechanism, is Acemoglu-Shimer (1999). They note that UI could have positive benefits in output under imperfect risk markets, because it induces risk-averse workers to choose more productive but more risky jobs. 
from consumption smoothing. In this paper, we provide a simple characterization of the optimal UI program in terms of these primitives, without restricting ourselves to special parameterizations of either. The resulting formulation allows us to analyze, for instance, how changes in risk aversion simultaneously affect both the marginal benefits of $\mathrm{UI}$ and its costs and to assess the extent to which earlier results are dependent on the special parameterizations employed.

\section{Model}

We assume a 2-period model in which a worker gets laid off from his previous job with a certain probability at the start of period 1 . At the same time, the worker is offered a reemployment opportunity. The probability that the worker is employed the first period at wage $W$ is denoted by $P_{1}$. The remaining workers are offered a job paying wage $w_{1}(<W)$, distributed with a distribution function $\mathrm{F}(.){ }^{25}$ If $\mathrm{w}_{1} \geq W_{R}$, the reservation wage, he accepts the job. His reservation wage is endogenous, a function of his expectations of the wage he can get in period $2 .{ }^{26}$ If he accepts it, he gets employed at the wage in both periods. If he rejects it, he will be unemployed in period 1 , while searching for a favorable reemployment opportunity for period 2. The wage offer a worker receives after job search is variable: more specifically, he could get a job with wage $\mathrm{W}$ with probability $P_{2}$ or a job with wage $w_{2}(<W)$ with probability $\left(1-P_{2}\right)$. (See

Figure 1.) 2728

\footnotetext{
${ }^{25}$ The low wage job can be thought of as being in the informal sector. Accordingly, later in the paper, we assume that those workers do not pay the unemployment insurance tax. If the individual always finds some job, it means that $w_{1}>0 . F(0)$ is the probability of finding no job.

${ }^{26}$ As we noted in the introduction, this paper focuses on the incidence of unemployment. We postpone until section VII the possibility that $P_{1}$ or $\mathrm{F}$ is affected by the intensity of job search.

${ }^{27}$ This simplifies the presentations of the results. Allowing the second period wage offer $w_{2}$ to be variable would not affect any result in this paper. As the second period is the last period in the model an individual would obviously not turn down a job offer in the hopes of getting a better offer later, though he might turn down a wage offer that is so low that he would prefer to remain unemployed. In a fully articulated dynamic model, the wage offer might be so low that the individual would refuse it or he may get no job offer. Then the initial job loss can lead to either short-term or long-term unemployment. Note, however, that even in this simplified model, job search in the first period entails risks, not just in terms of duration of unemployment, but in terms of future wage variability.

${ }^{28}$ In section VII we assume $P_{2}$ varies with the individual's level of search effort.
} 
The initial loss of a job thus may lead to lower wages or to unemployment. Some of what happens is out of his control (the initial unemployment shock) and some is affected by his decisions about job acceptance and search.

Individuals maximize expected utility over the two periods of the model. For simplicity, we assume an additive separable utility function with no discounting, where the utility function (of consumption) each period is the same. For simplicity, we assume that individuals can neither save nor borrow, so consumption is equal to wages (adjusted for taxes or UI benefits). ${ }^{29}$ The loss of a job creates income differentials between states when the worker gets re-employed at the old wage and other states; unemployment-not getting a wage offer above one's reservation wage-creates income (and more importantly, consumption) differentials with future periods. Government-provided unemployment support can enhance welfare by reducing the cross-state and cross-period consumption differentials and possibly by inducing more socially desirable choices of search by individuals. But there is also the possibility that it will induce less socially desirable choices.

We proceed in our analysis in steps: first we analyze the equilibrium with no government intervention; then, as a benchmark, with optimal government intervention in the absence of moral hazard; then, we consider the equilibrium with only UI, before turning to the general cases with UI and ICL.

\section{III-1. Case with No Government Intervention}

The expected utility $V$ of a worker is

(1) $\mathrm{V}=2 P_{1} \mathrm{U}(\mathrm{W})+\left(1-P_{1}\right) V_{1}$

\footnotetext{
${ }^{29}$ We assume no intertemporal or interstate smoothing occurs beyond that provided by UB. Introducing savings greatly complicates the analysis, but does change the qualitative results. If individual's second period job prospects are sufficiently good, individuals would not want to save, even if they could. As we noted in the introduction, if individuals could borrow when unemployed, they might wish to borrow some amounts; but because of the risk of default and the risk premia lenders charge, the amounts would be limited and there would still be incomplete consumption smoothing. Stiglitz-Yun (2013) explores the interactions between private savings and borrowing and public programs.
} 
where $V_{1}$ is the expected utility for a worker who fails to get an offer $W$. The reservation wage determines whether or not he is unemployed in period 1. Thus,

(2) $V_{1}=\operatorname{Max}_{W_{R}} \int_{W_{R}}^{W}\left\{2 U\left(w_{1}\right)\right\} d F+F\left(W_{R}\right) V_{U}^{N}$,

where $V_{U}^{N}$ is the expected utility of a worker choosing to be unemployed in period 1 with no unemployment benefit:

(3) $V_{U}^{N}=\left[U(0)+P_{2} U(W)+\left(1-P_{2}\right) U\left(w_{2}\right)\right] \cdot{ }^{30}$

Finally, the reservation wage $W_{R}^{N}$ will be chosen by the worker so as to maximize $V_{1}$, implying:

(4) $2 U\left(W_{R}^{N}\right)=V_{U}^{N}$.

That is, $W_{R}^{N}$ is chosen such that the utility of working at the low wage job in period 1 and 2 is equal to the expected utility $V_{U}^{N}$ of being unemployed in period 1, and looking for a better job. ${ }^{31}$ The reservation wage $W_{R}^{N}$ is thus a consumption-smoothing mean ${ }^{32}$ of income for a worker who has variable incomes across states and between periods.

We represent the concavity of his utility function $U($.$) , by the measure of (relative) risk-aversion$ $\alpha,{ }^{33}$ i.e., $\alpha=-\frac{U^{\prime \prime} C}{U^{\prime}}$. From (3), the more concave (the more risk averse the individual), the lower the consumption-smoothing mean for a given risky wage profile. Individuals who are more risk averse are more concerned with consumption smoothing over time. We thus obtain

\footnotetext{
${ }^{30}$ Here and elsewhere, the superscript $\mathrm{N}$ denotes the value of a variable in an equilibrium with no government intervention. We assume that $\mathrm{U}(0)$ and $\mathrm{U}^{\prime}(0)$ are finite.

${ }^{31}$ In the absence of unemployment insurance, if $\mathrm{U}^{\prime}(0)$ is large enough, $W_{R}^{N}=0$. If individuals have a backstop source of income, then $W_{R}^{N}>0$. For the remainder of the paper we assume that is the case. It should be obvious that the individual's second order condition is always satisfied at (4).

${ }^{32}$ The consumption smoothing mean will be the same as a certainty equivalent in the case of state-wise consumption differentials. The certainty equivalent wage is the wage that gives the same expected utility as the random consumption; the consumption-smoothing mean is the fixed consumption which gives the same utility as the time and state varying consumption. Later, when we introduce explicit search costs, it will be apparent that the reservation wage takes into account the cost of search that will be required to obtain the job.

${ }^{33}$ One utility function is more concave (risk averse) than another if it can be derived from the first by a concave transformation, i.e. $\widehat{U}$ is more risk averse than $U$ if $\widehat{U}=\Phi(U)$ where $\Phi^{\prime \prime} \leq 0$ and for at least some values of $U, \Phi^{\prime \prime}<0$.
} 


\section{Proposition 1}

(5) $\frac{\partial W_{R}^{N}}{\partial \alpha}<0$

More risk-averse workers have a lower reservation wage-because the expected utility if they search is so low (because they put more weight on the possibility of the bad outcome), they are more willing to accept a bad deal today. Thus, the incidence of search is lower. We express the dependence of $W_{R}^{N}$ on $\alpha$, by writing $W_{R}^{N}(\alpha)$.

Before introducing $\mathrm{UI}$ in the model, we will first characterize the first-best outcome where government could control all the relevant variables (in particular, the incidence of search).

\section{III-2. First-best Outcome}

In the first-best outcome, the government specifies $W_{R}$ and $C_{0}$ and $C_{R}$, the first-period consumption levels for a worker who avoids unemployment by accepting $W$ and $w_{1}$ in period 1 , respectively, and $C_{1}, C_{\mathrm{g}}$ and $C_{\mathrm{b}}$ the first-period consumption of an unemployed worker, and the second-period levels of consumption of the worker who is reemployed in period 2 at $\mathrm{W}$ and $w_{2}$, respectively, subject to the resource constraint

(6) $2 P_{1} W+\left(1-P_{1}\right)\left[2 \int_{W_{R}}^{W} w_{1} d F+F\left(W_{R}\right)\left\{P_{2} W+\left(1-P_{2}\right) w_{2}\right\}\right]$

$$
=2 P_{1} C_{0}+\left(1-P_{1}\right)\left[2 \int_{W_{R}}^{W} C_{R} d F+F\left(W_{R}\right)\left\{C_{1}+P_{2} C_{\mathrm{g}}+\left(1-P_{2}\right) C_{\mathrm{b}}\right\}\right]
$$

It is straightforward to show that there is complete consumption smoothing across states and dates; denoting by a caret the value of the relevant variables in the first-best:

(7) $\hat{C}_{0}=\hat{C}_{R}=\hat{C}_{1}=\hat{C}_{\mathrm{g}}=\hat{C}_{\mathrm{b}}=P_{1} W+\left(1-P_{1}\right)\left[\left(1-F\left(\widehat{W}_{R}\right)\right) W\left(\widehat{W}_{R}\right)+\frac{1}{2} F\left(\widehat{W}_{R}\right) \bar{W} \equiv \hat{C}\right.$

The reservation wage is set so that

(8) $2 \widehat{W}_{R}=\bar{W}$

where 
(9) $\bar{W} \equiv P_{2} W+\left(1-P_{2}\right) w_{2}$,

the expected income of an unemployed worker when he gets a job. The first-best choice of $\widehat{W}_{R}$ is not affected by the utility function $\mathrm{U}($.), but rather is chosen to maximize the expected income of those who do not get a job at $\mathrm{W}$ the first period, denoted by $\widehat{G}$.

(10) $\hat{G} \equiv\left[2 \int_{W_{R}}^{\bar{W}} w_{1} d F+F\left(W_{R}\right)\left\{P_{2} W+\left(1-P_{2}\right) w_{2}\right\}\right]$

Maximizing $\hat{G}$ with respect to $W_{R}$ generates (8). If search is costless, then the reservation wage, the wage at which the individual is indifferent between searching and not-searching, should be such that the gain from search, $\bar{W}-\widehat{W}_{R}$ should be equal to the opportunity cost of searching, $\widehat{W}_{R}: \bar{W}-\widehat{W}_{R}=\widehat{W}_{R}$, from which (8) follows immediately. Since

$$
\mathrm{GDP} \equiv \mathrm{G}=2 P_{1} W+\left(1-P_{1}\right) \widehat{G}
$$

with fixed $P_{1}$, maximizing $\hat{G}$ is equivalent to maximizing $\mathrm{G}$.

We note that with optimal search, there is no simple relationship between the average wages of those who accept a job the first period

(11) $W\left(\widehat{W}_{R}\right) \equiv \frac{1}{1-F\left(\widehat{W}_{R}\right)} \int_{\widehat{W}_{R}}^{W} w_{1} d F$,

and those who accept the second period, $\bar{W}$. This is true more generally, with costly search, in the presence of $\mathrm{UI}$, and with probability distributions of job offers that differ between periods.

Comparison of first-best search and search with no unemployment insurance

While the $W_{R}$ chosen to maximize $\mathrm{G}$ is the same as that maximizing welfare in the first-best world, that will not be the case when the choices (actions) of individuals are not monitored (so there is moral hazard), and when individuals are risk-averse and there is incomplete insurance.

Proposition 2 ascertains how risk aversion affects the reservation wage and G. .

\section{Proposition 2}

i) When $\alpha=0, W_{R}^{N}(0)=\widehat{W}_{R}$; for $\alpha>0, W_{R}^{N}(\alpha)<\widehat{W}_{R}$ 
ii) $\frac{\partial G^{N}}{\partial \alpha}<0$, where $G^{N}$ is GDP in the absence of government intervention .

Proposition 2i) says that when a worker is risk-neutral, the first-best choice $\widehat{W}_{R}$ will be realized in the market without government intervention. Because search is risky, a risk-averse worker has a lower reservation wage, thus searching less than would be the case in the first best, with the difference between the no-insurance search incidence and that with full insurance increasing with the level of risk aversion.

Proposition 2ii) says that GDP decreases with risk aversion. To see this, from (10)

(12) $\frac{d G}{d x}=f\left(W_{R}\right)\left\{\bar{W}-2 \mathrm{~W}_{\mathrm{R}}\right\} \frac{\partial \mathrm{W}_{\mathrm{R}}}{\partial x}$,

where here $x=\alpha$. Proposition 2i) implies that if $\alpha>0, \bar{W}-2 W_{R}^{N}>0$, and the result follows directly from Proposition 1. Those who criticize UI for discouraging search too often forget that the world with no-insurance generates inefficient outcomes; not even $\mathrm{G}$ is maximized.

\section{UI System}

Obviously it is not possible without full monitoring to achieve the first-best outcome ${ }^{34}$, because an individual worker does not have the right incentive to choose $\widehat{W}_{R}$ given $\left\{\hat{C}_{0}, \hat{C}_{R}, \hat{C}_{1}, \hat{C}_{g}, \hat{C}_{b}\right\}$. ${ }^{35}$ We need to have some consumption differentials between states and periods to support individual incentives for the choice of an appropriate reservation wage.

In this section, we analyze how much unemployment insurance (UI) alone can do to improve welfare and how GDP (as defined above) is affected by the introduction of UI. The UI benefit, $r$, paid to the individual who rejects his wage offer is financed by taxes imposed on employed

\footnotetext{
${ }^{34}$ Outside a "command" economy in which the government could "order" individuals when to accept a job and how much to search (as is the case in our first-best outcome). Typically the government would not have enough information to implement the first-best outcome, even it had the power to force individuals to accept a particular job. It still might be possible in this simplistic setting through appropriately designed non-linear incentive structures to achieve this outcome. Here, we focus on more realistic linear systems (or on models in which the government has imperfect information about the relevant search functions, which might differ across individuals). ${ }^{35}$ In our formulation here, with no search costs, the individual is indifferent: in the first-best outcome, his expected utility does not depend on his reservation wage. But if there were an epsilon of unobserved search costs, then the individual would not want to search at all, which would clearly be inefficient.
} 
workers. The analysis is greatly simplified if we assume that the tax is only collected on those who continue in high-paying jobs. In appendix $B$, we show that the results are robust, e.g. to a tax system which imposes a tax $T$ on all those who are employed at W, i.e. including those who have gone through a period of unemployment. ${ }^{36}$

Welfare maximization entails choosing the unemployment benefit to maximize the expected utility of a worker, recognizing that as $r$ changes, individuals change their reservation wage $W_{R}$ and the $\operatorname{tax} T$ has to change to satisfy the government budget constraint.

Analytically, this is a standard indirect control problem, where individuals are choosing their six decisions variables $\left\{C_{0}, C_{R}, C_{1}, C_{g}, C_{b}, W_{R}\right\}$ subject to their budget constraints, and the government chooses $\left(r^{o}, T^{o}\right)$, subject to its budget constraint (itself affected by the decisions of individuals). We solve for the resulting eight equations in eight unknowns, and perform comparative statics on the system. At first blush, the problem would seem almost intractable; but fortunately, the simplifying assumptions we have made allow us to derive some strong, interesting, and general results. We proceed by describing individual's responses to the UI system, and then embedding those responses as constraints in the social welfare maximization problem.

The optimal UI benefit $r^{o}$ maximizes lifetime utility $\mathrm{V}$ :

(13) $\mathrm{V}=\left\{2 P_{1} \mathrm{U}(\mathrm{W}-\mathrm{T})\right\}+\left(1-P_{1}\right)\left[\int_{W_{R}}^{W}\left[2 U\left(w_{1}\right)\right] d F+F\left(W_{R}\right) V_{U}(r)\right]$

where the expected utility $V_{U}(r)$ of an unemployed worker with $\mathrm{UI}$ benefit $r$ is

$$
V_{U}(r)=U(r)+P_{2} U(W)+\left(1-P_{2}\right) U\left(w_{2}\right)
$$

\footnotetext{
${ }^{36}$ In general, with imperfect capital markets, UI provides intertemporal as well as interstate smoothing, i.e. between consumption in the first period of the unemployed and his consumption in the second. The extent to which it does each can be affected by how UI is financed. With the wage tax system that imposes the tax on all workers employed at W, for example, the optimal UI is shown (in Appendix B) to entail a combination of the two types of smoothing; in the particular case when $P_{1}$ is close to 1 , i.e., when the portion of the population that is unemployed is very small, the optimal UI approaches the Chetty-Baily rule as it provides mostly interstate smoothing (with little intertemporal smoothing). Further extensions to the case where a tax may be imposed on those employed at lower-wage jobs are easily introduced into the model. In still more general models, unemployment benefits are directly related to the pre-unemployment wages.
} 
subject to the incentive constraint for the choice of the reservation wage, which now takes the form of :

$$
2 \mathrm{U}\left(W_{R}\right)=V_{U}(r)
$$

and to the government budget constraint

$$
2 P_{1} T=\left(1-P_{1}\right) F\left(W_{R}\right) r
$$

Impact of risk aversion and unemployment insurance on the Reservation Wage and GDP

Substituting (16) into (15), and the result into (14), we can solve for $W_{R}$ simply as a function $r$, which we write as $W_{R}(r)$. We can then solve for the probability that an individual searches, rather than accepting a job-determining the unemployment rate, as a function of $r: F\left(W_{R}(r)\right)$. It follows from (15) that an increase in the unemployment benefit increases the reservation wage, as expected:

$$
\frac{d \ln W_{R}}{d \ln r}=\frac{r U^{\prime}(r)}{2 \mathrm{U}^{\prime}\left(W_{R}\right) W_{R}} \quad>0
$$

(For later reference, we note that $\frac{d \ln W_{R}}{d \ln r}>$ or $<\frac{1}{2}$ as $(1-\alpha)\left(r-W_{R}\right)>$ or $<0$.) It is immediate from (14) and (15) that an increase in risk aversion lowers $V_{U}(r)$ for any given $r$, and hence lowers the reservation wage. For any $r$, there is a critical value of $\alpha, \hat{\alpha}(r), \hat{\alpha}(r)>0$, such that for $\alpha \geq \hat{\alpha}(r), W_{R}(r) \leq \widehat{W}_{R}$. Conversely for $\alpha<\hat{\alpha}(\mathrm{r})$. Alternatively, for given $\alpha$, we can define $\hat{r}(\alpha) \equiv \hat{\alpha}^{-1}(\alpha)$, the level of $r$ that induces the choice of $\widehat{W}_{R}\left(=\frac{\bar{W}}{2}\right)$ by a worker with riskaversion $\alpha$, where $\hat{r}(0)=0$ and $\hat{r}^{\prime}(\alpha)>0$, so that $\hat{r}(\alpha)>0$ for $\alpha>0$.

Denoting by $G(r ; \alpha){ }^{37}$ the level of GDP at $U I r$ for a given risk-aversion $\alpha$, from (10),

$$
\frac{d G}{d r}>0 \text { for } r<\hat{r}(\alpha), \frac{d G}{d r}=0 \text { for } r=\hat{r}(\alpha) \text {, and } \frac{d G}{d r}<0 \text { for } r>\hat{r}(\alpha)
$$

\footnotetext{
${ }^{37}$ In the presence of unemployment insurance, (10) and (10') still hold, with $W_{R}$ a function of $r$.
} 
We have thus far established the following Proposition.

\section{Proposition 3.}

(i) An increase in $r$ increases the reservation wage.

(ii) An increase in $r$ up to a certain threshold $(\hat{r}(\alpha))$ increases search, moving individuals towards the first best level of search, and increases GDP, and beyond that decreases search and GDP. For any given $\alpha, G(r, \alpha) \leq G(\hat{r}(\alpha), \alpha)$ for all $r$, and there exists a $\tilde{r}(\alpha)>$ $\hat{r}(\alpha)$ such for $r<\tilde{r}(\alpha), G(r, \alpha)>G(0, \alpha)$, i.e. the provision of UI increases GDP.

Thus, a small UI program both improves consumption smoothing and GDP. Of course, even when unemployment insurance lowers $\mathrm{G}$, (by definition) the optimal unemployment insurance system increases societal welfare. This should come as no surprise. We know that markets in which there are information asymmetries, search, and imperfect risk markets are essentially never (constrained) Pareto efficient. ${ }^{38}$ Our analysis has shown one particular way in which government intervention can increase welfare-through the provision of unemployment insurance.

The percentage change in search incidence from a percentage change in $r$ is just equal to $W_{R} \frac{f}{F} \frac{d \ln W_{R}}{d \ln r}=H \frac{d \ln W_{R}}{d \ln r}$, where $\mathrm{H}=W_{R} \mathrm{f} / \mathrm{F}$. This depends on $\frac{d \ln W_{R}}{d \ln r}$ and the logarithmic derivative of F. From (17), the magnitude of the increase in the reservation wage from an increase in $r$ depends critically on the value of $r$ relative to $W_{R} \cdot \frac{d \ln W_{R}}{d \ln r}$ can be either small or large. If prospects next period are good enough and individuals are not too risk averse, then for small enough $r, W_{R}>>r$, and $\frac{d W_{R}}{d r}$ is large. If $r$ is relatively large, there is a significant prospect of not

\footnotetext{
${ }^{38}$ Moreover, again partly because of information imperfections and asymmetries, governments impose taxes on income (rather than lump sum taxes), so that the social benefits of getting a job are greater than the private benefits, and this gives rise to underinvestment in search. If this were the only distortion, then individuals would be searching too little, and governments would strive for policies which increased the reservation wage, as UI does in our model. We do not pursue the implications of this distortion in this paper.
} 
being able to get a good job next period, and risk aversion is large enough, then $W_{R}<r$, and $\frac{d W_{R}}{d r}$ will be small.

The Optimal Unemployment Insurance system

The optimal unemployment insurance system balances the marginal benefit of an increase in $r$ $\left(\frac{d V_{U}}{d r}\right)$ against the marginal cost resulting from the increased taxes required to finance it (the tax externality, which individuals, in making search decisions, don't take into account).

Differentiating expected utility $\vee$ with respect to $r$, and making use of the envelope theorem, we obtain for the first order condition defining $\left\{r^{\circ}, T^{\circ}\right\}$,

(19) $\left(1-P_{1}\right) F\left\{U^{\prime}\left(r^{o}\right)-U^{\prime}\left(W-T^{o}\right)\right\}=\frac{\partial V}{\partial T} \frac{d T}{d W_{R}} \frac{d W_{R}}{d r}$

where

(20a) $\frac{d T}{d W_{R}} \frac{d W_{R}}{d r}=\frac{1-P_{1}}{2 P_{1}} \mathrm{r} f \frac{U^{\prime}(r)}{2 U^{\prime}\left(W_{R}\right)}$ and (20b) $\frac{\partial V}{\partial T}=2 P_{1} U^{\prime}\left(W-T^{o}\right)$,

so the RHS of (19) is

(21) $\left(1-P_{1}\right) \mathrm{rf} \frac{U^{\prime}(r)}{2 U^{\prime}\left(W_{R}\right)} U^{\prime}\left(W-T^{o}\right)$.

The LHS of (19) is the marginal benefit of increasing $r$-better interstate smoothing (the difference between the marginal utility in the unemployed state and the marginal utility in the "good" state) at a fixed tax rate, while the RHS is the social cost of increasing the tax rate.

Expressing $T$ as a function of $r$, from (16), and taking the derivative (using 17), we obtain

$\left(16^{\prime}\right) T=\frac{\left(1-P_{1}\right) F\left(W_{R}\right) r}{2 P_{1}}$, and $\left(16^{\prime \prime}\right) \frac{d T}{d r}=\frac{\left(1-P_{1}\right) f\left(W_{R}\right) r}{4 P_{1}} \frac{U^{\prime}(r)}{U^{\prime}\left(W_{R}\right)}+\frac{\left(1-P_{1}\right) F\left(W_{R}\right)}{2 P_{1}}>0$,

The marginal benefit of smoothing $\left\{U^{\prime}\left(r^{o}\right)-U^{\prime}\left(W-T^{o}\right)\right\}$ diminishes in $r$, but the greater $r$, the more frequently is smoothing relevant (the greater $F$ ), because the higher the reservation wage. Moreover, the marginal distortion from the tax externality may increase or decrease in $r$. 
While $\left\{r U^{\prime}\left(W-T^{o}\right)\right\}$ increases with $r, f \frac{U^{\prime}(r)}{2 U^{\prime}\left(W_{R}\right)}$ may increase or decrease. Thus there may be multiple solutions to (19). This greatly complicates the comparative statics analysis. Still, substituting (20a) into (19) and evaluating at $r=0$ and observing that with complete smoothing, the marginal benefit of smoothing is zero, i.e. the LHS is zero, while the RHS is positive, so long as $f>0$ in the relevant range we can establish

\section{Proposition 4}

$$
0<r^{o}<W-T^{o}
$$

It is optimal to have some unemployment insurance, but there is always incomplete income smoothing.

\section{Comparative statics}

Any change in parameters which, at a fixed $r$ and $F$, increases (decreases) the reservation wage increases taxes, $T$, and therefore reduces (increases) the benefits of income smoothing. If that change not only increases (decreases) the tax but also increases (decreases) the marginal externality cost associated with an increase in $r$, as one might well expect, then the optimal $r$ unambiguously results in a reduced (increased) level of unemployment insurance.

Unfortunately, even for our highly idealized model, establishing clean and general results for changes in many of the key parameters turns out to be difficult. To some extent, this should not be a surprise, given that the first-order condition for $r$ imbeds incentive effects. For instance, some parameters like $\mathrm{P}_{2}$ or $\alpha$ would induce changes in individual choices of reservation wages, which could affect positively or negatively the marginal externality cost relative to the incomesmoothing benefit. Also, if we write the distribution function $\mathrm{F}$ as a function of a parameter $\beta$, $\mathrm{F}(; \beta)$, then a change in $\beta$ may affect the externality costs while leaving $W_{R}(r)$ unchanged. Below, we parse out these various effects, identifying circumstances in which we can sign $\frac{d r}{d \beta}$ as well as the effect of an increase in $P_{1}, P_{2}$, or $\alpha$. 
What matters, of course, is how a parameter change alters marginal smoothing benefits relative to its impact on the marginal externality, and to ascertain that, it is convenient to rewrite (19), using (20) as

$$
\frac{U^{\prime}\left(r^{0}\right)-U^{\prime}\left(W-T^{0}\right)}{U^{\prime}\left(W-T^{o}\right)}=r^{o} \mathrm{H}\left(W_{R}\right) \frac{U^{\prime}\left(r^{o}\right)}{2 U^{\prime}\left(W_{R}\right) W_{R}}
$$

with the LHS reflecting the benefits of an increase in $r$ and the RHS the costs. (22) can be solved for $r^{\circ} .39$

$$
\left(22^{\prime}\right) r^{o}=\frac{\frac{U^{\prime}\left(r^{0}\right)-U^{\prime}\left(W-T^{0}\right)}{U^{\prime}\left(W-T^{o}\right)}}{\mathrm{H}\left(W_{R}\right) \frac{U^{\prime}\left(r^{o}\right)}{2 U^{\prime}\left(W_{R}\right) W_{R}}}
$$

Equation (22) is an analogue of the optimal formula of Baily (1978) and Chetty (2006) with a couple of important differences: Our focus here is on search incidence rather than search effort. ${ }^{40}$ And rather than expressing the optimal $r$ in terms of a search elasticity, we express it in terms of the underlying primitives that determine the search elasticity, highlighting (a) the distribution of quality of job offers matters ; and (b) the optimal UI has to consider the endogenous setting of reservation wages, which affects the value of the search elasticity both directly and indirectly, through its impact on $\mathrm{H}\left(W_{R}\right)$.

From (22), in the limiting case, as $H\left(W_{R}\right)$ goes to zero, so there is no response of search to UI, not surprisingly, $\mathrm{U}^{\prime}\left(\mathrm{r}^{\circ}\right)$ goes to $U^{\prime}\left(\mathrm{W}-\mathrm{T}^{0}\right)$, i.e. there is full consumption smoothing between the unemployed state and the state where there is re-employment at full-wages $W$. In the other limiting case, as $H\left(W_{R}\right)$ goes to infinity, so the search elasticity gets very large, $r$ goes to zero. ${ }^{41}$ A sufficient but not necessary condition for the second-order condition for $r^{0}$ to be satisfied is

\footnotetext{
${ }^{39}$ It should be noted however that the RHS of (22') depends on $r$ through T. Similarly, while it appears as if $r$ depends just on $H$ (which depends on $\beta$ ), note that $T$ depends on $F$, which depends on $\beta$. Thus $\beta$ affects $r^{\circ}$ both through its effects on $\mathrm{F}$ directly and (possibly) through its effects on $\mathrm{H}$.

${ }^{40}$ This can be seen most clearly by rewriting (22) as: $\frac{U^{\prime}\left(r^{o}\right)-U^{\prime}\left(W-T^{o}\right)}{U \prime\left(W-T^{o}\right)}=H\left(W_{R}\right) \frac{d \ln W_{R}}{d \ln r}=\frac{d \ln F}{d \ln r}$ We add search effort in Section VII.

${ }^{41}$ Using $\left(22^{\prime}\right)$ assume $r$ does not converge to 0 as $\mathrm{H}$ gets large. $W_{R} \geq \min \left\{r^{o}, w_{2}\right\}, \mathrm{U}^{\prime}\left(W_{R}\right)$ is finite, and it follows that $\operatorname{limit} r^{o}$ is zero.
} 
that the RHS of (22), reflecting the marginal externality cost, is increasing in $r$, and a sufficient condition for this is that $\mathrm{dln} \mathrm{H} / \mathrm{ln} \mathrm{w}$ is not too negative or, more precisely,

$\left.\frac{d \ln H}{\operatorname{dln} W_{R}}\right|_{W_{R}=W_{R}^{o}}>1-\alpha\left(W_{R}^{o}\right)$

Appendix $A 1$ shows that $A$ is a sufficient condition for the SOC, but that $S O C$ may be satisfied even when $A$ is not satisfied. Note that the LHS is a property of the probability distribution of job offers, the RHS a property of the utility function, so A might well not be satisfied.

Assumption $(A)$ will be used to derive the key comparative statics, the results of which are summarized in

\section{Proposition 5 (Comparative statics)}

i) $\frac{d r^{o}}{d P_{1}}>0$,

An increase in $P_{1}$ (the probability of getting wage $W$ in the first period) increases UI. It lowers the tax and leaves search unaffected at any r. Thus the RHS of (22) (reflecting the marginal cost of increasing $\mathrm{UI}$ ) at any $r$ is unchanged; the LHS (reflecting the marginal benefits) is increased, so $r^{0}$ is unambiguously increased.

ii) $\quad \frac{d r^{o}}{d \beta}>0$ if $\mathrm{H}_{\beta} \leq 0$ and $\mathrm{F}_{\beta} \leq 0^{43}$ (with one inequality holding strictly); or if $\mathrm{r}^{\circ}$ is small and $F_{\beta}<0 ; \frac{d r^{o}}{d \beta}<0$ if $\mathrm{H}_{\beta} \geq 0$ and $\mathrm{F}_{\beta} \geq 0$ (with one inequality holding strictly); or if $\mathrm{r}^{\circ}$ is small and $F_{\beta}>0$. As a limiting case, if $\mathrm{H}_{\beta} \rightarrow \infty, r^{o} \rightarrow 0$.

Clearly, the optimal UI should change with wage-offer distributions facing an unemployed worker, but the relationship is complex. Changes in F affect (22) both through the impact on the reservation wage (and hence on $\mathrm{T}$ ) and $\mathrm{H}$ (affecting the marginal externality). If $r^{0}$ is

\footnotetext{
${ }^{42}$ For plausible wage distributions (such as the lognormal) and plausible values of relative-risk aversion, the condition will be satisfied if $r$ is not too small. When this condition is not satisfied, while the marginal benefit of an increase in $\mathrm{Ul}$ increases with $\alpha$, the marginal distortion may as well.

${ }^{43} \mathrm{H}_{\beta}$ and $\mathrm{F}_{\beta}$ are related: $\mathrm{H}_{\beta} / H=\mathrm{f}_{\beta} / \mathrm{f}-\mathrm{F}_{\beta} / F$; but it is clear that they can have markedly different values, or even signs.
} 
small ${ }^{44}$, the effects on the LHS dominate, so $r^{0}$ increases (or decreases) as $F_{6}$ is less than (or greater than) zero. For that to be still true when $r^{0}$ is not small, we also require that $\mathrm{H}_{6}$ also be less than (or greater than) zero. ${ }^{45}$

Suppose that the assumption (A) holds or that $r^{o}$ is small. ${ }^{46}$ Then,

(iii) $\frac{d r^{o}}{d P_{2}}<0$ and $\frac{d r^{o}}{d w_{2}}<0$

Under the stipulated conditions, as increase in the probability of getting a good job the second period or an increase in the wages in the "bad" job leads to a lower level of UI. An increase in $P_{2}$ or in $w_{2}$ increases $V_{U}(r)$, and thus $W_{R}(r), \mathrm{F}$ and T. An increase in $P_{2}$ or $w_{2}$ reduces the LHS of (22) while under assumption A or if $r^{0}$ is small, increasing the RHS.

(iv) $\frac{d r^{o}}{d \alpha}>0$.

An increase in risk aversion increases the optimal UI. An increase in risk-aversion $\alpha$ lowers $W_{R}$ and thereby increases the LHS of (22) and under the stipulated conditions decreases the RHS.

The proofs of Proposition 5 (iii) and (iv) can be found in the Appendix A2, where we also show that the SOC can be satisfied but $\left.\frac{d \ln H}{\operatorname{dn} W_{R}}\right|_{W_{R}=W_{R}^{o}}<1-\alpha\left(W_{R}^{o}\right)$. When $(\mathrm{A})$ is not satisfied by a large amount (i.e. , $\left.\frac{d \ln H}{d \ln W_{R}}\right|_{W_{R}=W_{R}^{o}}$ is sufficiently greater than $1-\alpha\left(W_{R}^{o}\right),{ }^{47}$ and $r^{0}$ is not small, the comparative static effects of a change in $P_{2}, w_{2}$, and $\alpha$ are reversed. Thus, while an increase in risk aversion increases the benefit of consumption smoothing, that change may also increase the deadweight loss from the tax externality in a more than offsetting way, leading to a reduction in UI.

\footnotetext{
${ }^{44}$ We have already shown that that will be true if $H\left(W_{R}\right)$ is sufficiently large.

${ }^{45}$ Earlier literature, Baily (1978), did not emphasize the critical role of the wage distribution in determining the marginal cost of increasing the unemployment benefit.

${ }^{46}$ The condition on $r^{0}$ is, of course, not a restriction on the primitives; it follows from (22) if, for instance, $\mathrm{H}\left(W_{R}\right)$ is large.

${ }^{47}$ But not so much that the SOC is violated. The key observation is that the SOC does not suffice to sign the comparative statics.
} 


\section{Approximations for small risk}

We can see this by taking a Taylor series approximation to $\left(22^{\prime}\right)$ around $W-T^{0}$, and defining $z=\frac{r^{0}}{W-T^{0}}$, the replacement rate; and $\lambda=\frac{W_{R}}{W-T^{0}}$, the ratio of the reservation wage to the (after tax) wage in the formal sector; then

$\left(22^{\prime \prime}\right) \alpha(1-z)=\frac{\mathrm{Hz}}{2 \lambda}\left[\frac{1+\alpha(1-z)}{1+\alpha(1-\lambda)}\right]$

The LHS of the expression is what we see in the Baily-Chetty formulation. The RHS is typically expressed in terms of the elasticity of search (or some similar concept) with respect to UI. While the Baily-Chetty formulation has the advantage of expressing the optimal replacement rate in terms of an empirically observable parameter, using an estimate based on past data may be misguided, for policy interventions (an optimal UB program) will in general change the search elasticity. ${ }^{48}$ Our model allows us to understand the underlying determinants of the search elasticity, and therefore analyze the forces that govern the replacement rate.

For instance, consider the effect of risk aversion. (22") gives a quadratic function of $\mathrm{z}$, which can be solved for $z(\alpha)$. It can be shown that $z^{\prime}(\alpha)>0$, i.e. an increase in risk aversion, increases the replacement rate. ${ }^{49}$

But consider the role of future prospects is captured in $\lambda$ : the LHS is not affected by it but the nRHS changes in complex ways. By taking the derivative w.r.t. $\lambda$ and evaluating at $z^{*}$ (the solution to $\left.\left(22^{\prime \prime}\right)\right)$ we can show that an improvement in future prospects, increasing $\lambda$, increases or decreases $z$ as $\lambda<$ or $>(1+\alpha) / 2 \alpha$. Since $\lambda<1$, if $\alpha<1$, an improvement in future prospects induces a higher replacement rate-inducing individuals to undertake more search risk. But if individuals have high enough risk aversion, just the opposite happens.

\footnotetext{
${ }^{48}$ In macroeconomics, the observation that policy will affect reduced form behavioral estimates, and therefore one cannot rely on past estimates, is, of course, the famous Lucas critique.

49 The quadratic equation is $\psi \equiv H \alpha z^{2}-z\{2 \lambda \alpha[1+\alpha(1-\lambda)]+\mathrm{H}(1+\alpha\}+2 \alpha \lambda[1+\alpha(1-\lambda)]=0$. It is easy to show that a $z=0, \psi>0$ and at $z=1, \psi<0$, implying that there is a unique value of $z$ for which $\psi=0$ between 0 and 1. It can then be shown that an increase in $\alpha$ shifts $\psi$ up at $z^{*}$, and hence increases $z^{*}$, and whether an increase in $\lambda$ shifts $\psi$ up or down depends on the condition given in the text below.
} 


\section{Income-Contingent Loans}

Government-provided loans can also directly cope with the problem caused by the lack of intertemporal smoothing resulting from capital market imperfections. In earlier work (Stiglitz and Yun 2005, 2013) we showed how such loans could supplement, and in some limiting cases actually replace, UI. Here, we consider income-contingent loans where the amount repaid depends on the outcome of search, i.e. individual's future income. Contingent loans can reduce both interstate and intertemporal consumption differentials. We show that an ICL reduces the need for UI, but increases the reservation wage, thus increasing the incidence of search. While it accordingly increases unemployment, it increases welfare, and may even increase GDP.

Assume government provides an unemployed worker with loans $\mathrm{R}$ as well as unemployment insurance (UI). While the UI benefit $r$ does not have to be repaid, the amount repaid on an income-contingent loan, $\varphi(w)$, is contingent upon the second period wage w:

$$
\begin{aligned}
\text { (23) } \varphi(\mathrm{w}) & =R+\tau & & \text { for } \mathrm{w}=\mathrm{W} \\
& =R-D, & & \text { for } \mathrm{w}=w_{2}(<W)
\end{aligned}
$$

where $\tau$ is an additional payment that a worker reemployed with wage $\mathrm{W}$ makes to finance the cost of loan forgiveness and where $\mathrm{D}(\leq \mathrm{R})$ is the amount of loan forgiveness if the workers gets a low wage the second period. ${ }^{50} \mathrm{D}=0$ indicates a regular loan, without loan forgiveness. ${ }^{51}$

Here, we assume (as before) that the $U I$ benefit is financed by wage taxes, while the cost of $\mathrm{ICL}$ - the debt that is forgiven-- is totally financed by an additional interest premium $\tau$ charged on the debtors who are employed at the wage W, so

(24) $\tau=\frac{1-P_{2}}{P_{2}} \mathrm{D}$

\footnotetext{
50 The restriction that the amount of loan forgiveness is not greater than the loan $\mathrm{R}$ (i.e., $D \leq R$ ), that is, that a reemployed worker is not to be given an extra subsidy in addition to the loan forgiveness, limits the degree of interstate smoothing for the re-employed in period 2.

${ }^{51}$ It is easy to generalize the analysis here to allow $w_{2}$ to be variable and for $D$ to depend on $w_{2}$
} 
In section $\mathrm{VI}$, we show that this assumption does not limit the generality of our analysis. We first establish the desirability of introducing an ICL, and then provide a characterization of the optimal package of unemployment benefits (UB) while examining its welfare performance relative to the optimal UI system.

\section{V-1. Welfare Effect of Introducing ICL}

We maximize the expected utility of a worker as a function of the four variables $\{r, T, R, D\}$ :

(25) $\mathrm{V}=2 P_{1} \mathrm{U}(\mathrm{W}-\mathrm{T})+\left(1-P_{1}\right)\left[\int_{W_{R}}^{W}\left[2 U\left(w_{1}\right)\right] d F+F\left(W_{R}\right) V_{U}(R, D ; r)\right]$

where expected utility of an unemployed individual $V_{U}(R, D ; r)$ with the UI benefit $r$ and contingent loan $R$ with debt forgiveness $D$ is

$$
V_{U}(R, D ; r)=\left[U(r+R)+P_{2} U(W-R-\tau)+\left(1-P_{2}\right) U\left(w_{2}-R+D\right)\right]
$$

subject to the financing constraints for $\mathrm{UI}$ and ICL and to the same incentive constraint for the choice of reservation wage $W_{R}$ :

(27) $2 \mathrm{U}\left(W_{R}\right)=\operatorname{Max}_{R, D} V_{U}(R, D ; r)$.

UB affects $V$ through its effect on $V_{U}$ and on $\mathrm{T}$ (both directly and indirectly through its effect upon $\left.W_{R}\right)$. The optimal ICL can be characterized by the condition that $\frac{d V_{U}}{d x}=0$ for $\mathrm{x}=\mathrm{R}, \mathrm{D}$. From (27) it is clear that $V_{U}$ determines $W_{R}$. Hence, given $V_{U}$, and thus $W_{R}, V$ is maximized when $r$ (and $\mathrm{T})$ are minimized, or equivalently, given $r$ and $W_{R}$, when $V_{U}$ is maximized. Hence, in the analysis below, we focus on the determination of $\{R, D\}$, given $r$ and $W_{R}$ (and thus $T$ ), and then on the optimal choice of $r$.

Suppose that $\mathrm{UI}$ is initially set to be at its optimal level $r^{o}$, as characterized by (22). ${ }^{52}$ At fixed $r$, $V_{U}$ is increased if we engage in consumption smoothing. At the unconstrained optimum,

\footnotetext{
52 Equation (22) looks as if $r^{\circ}$ does not depend on $\mathrm{R}$, but it does, indirectly, because $\mathrm{R}$ affects the reservation wage. We set $r^{\circ}$ at its optimal level, assuming $R=0$, and show that an increase in $R$ increases welfare.
} 
$W-R-\frac{1-P_{2}}{P_{2}} \mathrm{D}=w_{2}-R+D$, i.e. $W-w_{2}=D / P_{2}+T$, implying that

$$
D=\min \left\{R, P_{2}\left(W-w_{2}\right)\right\}
$$

so that for small $R, D=R$. More generally, (28) defines $D(R)$, and we can then use that to solve for $R(r)$. We have thus established

\section{Proposition 7 Optimality of debt forgiveness}

$\mathrm{D}(\mathrm{R})>0$ for any $\mathrm{R}>0$, while $\mathrm{D}(\mathrm{R})=\mathrm{R}$ when $\mathrm{R}(=\mathrm{R}(\mathrm{r}))$ is small $\left(\leq P_{2}\left(W-w_{2}\right)\right)$.

Proposition 7 says that any loan should involve some loan forgiveness for those who are reemployed at $w_{2}$ and that a small enough loan should be fully forgiven. ${ }^{53}$

In the discussion below, it will be useful to introduce the following notation:

$$
U_{o} \equiv U\left(C_{0}\right), U_{1} \equiv U\left(C_{1}\right), U_{g} \equiv U\left(C_{g}\right), U_{b} \equiv U\left(C_{b}\right)
$$

where $C_{0} \equiv W-T, \quad C_{1} \equiv r+R, \quad C_{g} \equiv W-R-\tau, \quad C_{b} \equiv w_{2}-R+D$.

Using this notation, a direct implication of Proposition 7 is:

$$
-U_{g}^{\prime}+U_{b}^{\prime} \geq 0
$$

with the inequality holding for the corner solution $D(R)=R$.

Increasing R from zero increases consumption smoothing and hence expected utility, i.e. at any given $\mathrm{r}, \frac{d V_{U}(R, D ; r)}{d R}>0$ at $\mathrm{R}=0$, and hence to attain a given $V_{U}(R, D ; r)$, we require a lower $\mathrm{r}$. Take a value of $r$ which leaves $V_{U}(R, D ; r)$ at the same level as it was without the ICL. Then, from (27), $W_{R}$ is unchanged, but that means that the tax rate $T$ is lower, and $V$ is higher:

\section{Proposition 8 Desirability of ICL}

\footnotetext{
${ }^{53}$ This result holds even when the probability $P_{2}$ of the wage offer $w_{2}$ in the second period is affected by the (unobserved) choice of search effort by an individual. See section VII below.
} 
It is always desirable to introduce an income-contingent loan as part of the unemployment benefits package.

This result is quite general, regardless of the value of any of the parameters in the model, including $P_{2}$. It also holds when the wage offer $w_{2}$ in the second period is affected by search effort (as discussed in section VII). ${ }^{54}$

\section{V-2. Effect on GDP of Introducing ICL}

From (12) we immediately obtain:

\section{Proposition 9 Effect of ICL on GDP}

Given UI $r$ that is lower than $\hat{r}(\alpha)$, introducing a small ICL increases GDP further.

\section{V-3. Characterizing the Optimal UB Package}

The analysis of the optimal UB program is parallel to that for the optimal UI program of the preceding section, except now there are three additional policy variables, the level of loans, $R$, the level of debt forgiveness, $D$, and the interest surcharge, $\tau--$ and one more financing constraint, (24). The analysis proceeds as earlier, with the government once again embedding individual's behavior in their optimization. Given the similarity between the two analyses, we focus our attention on the salient differences.

The optimal UB package, $\left\{r^{*}, T^{*}, R^{*}, D^{*}\right\}$, maximizes $\vee$ subject to the incentive constraint (27) and to the two financing budget constraints. Even with four policy variables (r, T, R, D), because of adverse incentives in the choice of the reservation wage there is far from complete insurance, leaving individuals still bearing risk.

\footnotetext{
${ }^{54}$ As in most of the optimal UI literature (with the exceptions noted earlier), we ignore private savings. This key proposition concerning the desirability of $\mathrm{ICL}$ also holds with private savings.
} 
In characterizing the optimal UB package we can write down the four first-order conditions, and solve simultaneously. But our formulation allows us to decompose the problem sequentially, solving backward for the optimal UB package.

Second-Period Problem for the optimal ICL $\{R(r), D(R(r))\}$

The second-period problem is for any $r$ to choose $\{R(r), D(R(r))\}$ that maximize $V_{U}(R, D ; r)$ subject to the financing constraint for ICL. Proposition 7 has defined D as a function of R. The optimal $\mathrm{R}$ for a given $\mathrm{r}$ is given by the condition that $\frac{d V_{U}}{d R}=\frac{\partial V_{U}}{\partial R}+\frac{\partial V_{U}}{\partial D}=0$ (when $\mathrm{D}(\mathrm{R})=\mathrm{R}$ ) or by the condition $\frac{d V_{U}}{d R}=\frac{\partial V_{U}}{\partial R}=\frac{\partial V_{U}}{\partial D}=0$ (when $\mathrm{D}(\mathrm{R})$ is an interior solution). In either case, the necessary condition for $R(r)$ is ${ }^{55}$

$$
U_{1}{ }^{\prime}-U_{g}{ }^{\prime}=0
$$

Thus, the optimal ICL entails either $U_{1}=U_{g}=U_{b}$ (complete consumption smoothing among these three states) or $U_{1}=U_{g}>U_{b}=U\left(w_{2}\right)$ (consumption smoothing between first period unemployed and those who get reemployed at $\mathrm{W}$ in the second period, with those who are reemployed at $w_{2}$ being worse off, even after full debt forgiveness.). With complete consumption smoothing

(32) $\mathrm{R}(\mathrm{r})=\frac{\bar{W}}{2}-\frac{r}{2} ; \mathrm{r}+\mathrm{R}(\mathrm{r})=\frac{r}{2}+\frac{\bar{W}}{2}=\bar{W}-R(r)$;

while with the more limited consumption smoothing

(33) $R(r)=\frac{W-r}{2} ; \quad R(r)+r=\frac{W+r}{2}=\mathrm{WR}(\mathrm{r})$

In either case, the optimal loan $R(r)$ is decreasing in $r$ while consumption in the unemployed state increases with $r$.

\footnotetext{
${ }^{55}$ With an interior solution, using the envelope theorem, $\frac{d V_{U}}{d R}=\frac{\partial V_{U}}{\partial R}=\left(U_{1}^{\prime}-U_{g}^{\prime}\right)=0$. With a corner solution $\mathrm{D}(\mathrm{R})=\mathrm{R}, U_{b}=U\left(w_{2}\right)$ and $U_{g}=U(W-R-\tau)=U\left(W-\frac{R}{P_{2}}\right)$, so that $\frac{d V_{U}}{d R}=\left(U_{1}^{\prime}-U_{g}^{\prime}\right)=0$..
} 
Once ICL or $\left(R(r), D(R(r))\right.$ ) is optimally chosen for a given $r$ as above, the corresponding $W_{R}$ (and thus $T$ ) can also be represented as a function of $r$. We will denote by $W_{R}(r)$ (or $T(r)$ ) the reservation wage (or the tax paid) under the optimally chosen ICL for a given $r$.

\section{First-Period Problem}

Using the envelope theorem (implying that $\frac{d V_{U}}{d R}=0$ ), we obtain, instead of (22)

(34) $\frac{1}{\left.U^{\prime}\left(W-T^{*}\right)\right)}-\frac{1}{U^{\prime}\left(r^{*}+R^{*}\right)}=r^{*} \mathrm{H} \frac{1}{2 U^{\prime}\left(W_{R}^{*}\right) W_{R}^{*}}$,

where $R\left(r^{*}\right)=R^{*}, W_{R}\left(r^{*}\right)=W_{R}^{*}$ and $T\left(r^{*}\right)=T^{*}$. Substituting (33) into (34), one can see that the second-order condition is satisfied under the assumption (A). Because $W_{R}$ is increased with more income contingent lending because of the improved smoothing between states " $\mathrm{g}$ " and "b", an increase in R reduces the LHS (related to the marginal smoothing benefit) and, provided condition A is satisfied, increases the RHS (related to the marginal distortion), so $r$ decreases.

We can now establish

\section{Proposition 10 Characterization of optimal UB and comparison with pure UI system}

(i) $R^{*}>0, \quad r^{*}>0$

Suppose the assumption $(A)$ holds. Then,

(ii) $r^{o}>r^{*}, R^{*}+r^{*}>r^{o}$

(iii) $\frac{d r^{*}}{d x}<0$ and $\frac{d R^{*}}{d x}>0$ for $x=P_{2}$ or $w_{2}$.

(iv) $\frac{d r^{*}}{d \alpha}>0$ and $\frac{d R^{*}}{d \alpha}<0$

We have already established the first sets of results, that there is both positive UI and ICL. The last three results depend on an increase in $W_{R}$ lowering the RHS, i.e. on assumption $\mathrm{A}$ being satisfied. If it is, the introduction of ICL lowers UI as it is substituted partially by loans. 
Moreover, consumption during the unemployed period is greater with ICL than with just UI.

(The argument is somewhat more complex, and presented in Appendix A3.) Also, more favorable post-unemployment prospects lower UI, since it induces more search, increasing the marginal cost of UI (the cost of the marginal distortion) and lowering the marginal benefit. Lower $r$ leads to increased loans, by (32) and (33). Finally, higher risk aversion leads to a greater reliance on $\mathrm{UI}$ and smaller loans if assumption $(\mathrm{A})$ holds as it increases the marginal benefit of insurance while lowering the reservation wage, and thereby lowering the marginal cost. V-4. Relative Performance of Optimal UB compared with Optimal UI

It is straightforward to show that the benefit from using ICL increases with individual's risk aversion. One can quantify the benefits along the lines of Arrow and Pratt's analysis of the cost of risk aversion: the fraction of an individual's income (in every state of nature) that the individual would be willing to give up in order to have the (optimally designed) UB program, with an ICL. Let $V^{*}\left(\lambda ; r^{*}, R^{*}, D^{*}\right)$ be the expected utility with an optimal UB program (and the associated taxes) and $\mathrm{V}^{\circ}$ be the maximized expected utility with just UI. Then the value of the $\mathrm{ICL}$ program is given by the solution to

$\mathrm{V}^{*}\left(\lambda^{*} ; r^{*}, \mathrm{R}^{*}, \mathrm{D}^{*}\right)=\mathrm{V}^{\circ}$,

i.e. $1-\lambda$ is the fraction of one's income one is willing to give away to get the better consumption smoothing from an ICL. It is a quantitative measure of the benefit of ICL.

It is straightforward to show ${ }^{56}$

\section{Proposition 11}

$(1-\lambda)$ is increasing in $\alpha$ and equals zero if $\alpha=0$.

Proposition 11 follows immediately from observing that an ICL is a mean-preserving reduction in risk. ${ }^{57}$

\footnotetext{
${ }^{56}$ For simplicity, for purposes of this analysis, we assume homothetic preferences, so that reducing an individual's prospects proportionately in all states leaves behavior (reservation wages) unchanged.

57 Using standard results from Rothschild and Stiglitz $(1970,1971)$ and Diamond and Stiglitz (1974).
} 


\section{Generality of Separate Financing Scheme}

In section $\mathrm{V}$ we assumed that the ICL was funded by imposing a higher interest rate on loans, what we call the separate financing scheme. But the results are more general. The ICL could be subsidized by the tax $T$ on those who get $W$ in the first period or a $\operatorname{tax} T_{g}$ on those who get the high-paid jobs the second. The expected utility $V$ of a worker can be written as

(35) $\mathrm{V}=2 P_{1} \mathrm{U}(\mathrm{W}-\mathrm{T})+\left(1-P_{1}\right)\left[\int_{W_{R}}^{W}\left[2 U\left(w_{1}\right)\right] d F+F\left(W_{R}\right) V_{U}\left(r, R, D, T_{g}\right)\right]$

where $V_{U}$ is the expected utility for an unemployed worker:

(36) $V_{U}\left(r, R, D, T_{g}\right)=U(r+R)+\operatorname{Max}_{e}\left[P_{2} U\left(W-R-T_{g}\right)+\left(1-P_{2}\right) U\left(w_{2}-R+D\right)\right]$,

The government constraint is now

$$
2 P_{1} T+\left(1-P_{1}\right) F\left(W_{R}\right) P_{2} T_{g}=\left(1-P_{1}\right) F\left(W_{R}\right)\left(r+\left(1-P_{2}\right) D\right)
$$

Define the net subsidy from first period workers to finance $2^{\text {nd }}$ period loan forgiveness (38a) $\Delta \equiv\left(1-P_{2}\right) D-P_{2} T_{g}$

and let

$$
r^{1} \equiv r+\Delta, \quad R^{1} \equiv R-\Delta, \quad D^{1}=D-\Delta
$$

We can then establish the following Proposition.

\section{Proposition 12}

For any putative optimal UB $\left(r *, R *, D *, T *, T_{g *}\right)$, the resulting consumption allocation can also be achieved by another $\operatorname{UB}\left(r^{1}, R^{1}, D^{1}, T^{1}, T_{g}^{1}\right)$, where $\left(r^{1}, R^{1}, D^{1}\right)$ is defined in (38) while $T_{g}^{1}=\frac{1-P_{2}}{P_{2}} D^{1}=\frac{1-P_{2}}{P_{2}}(D-\Delta)=\left(1-P_{2}\right)\left(D-T_{g}\right)$ and $T^{1}=\frac{\left(1-P_{1}\right) F}{2 P_{1}} r^{1}$.

The financing scheme denoted by superscript " 1 " is equivalent to that discussed earlier, where $\mathrm{ICL}$ is financed by a surcharge on the loan to finance loan forgiveness. The proof is simple. Note by (29) and (38b) that $C_{o}=C_{o}^{1}, C_{1}=C_{1}^{1}, C_{b}=C_{b}^{1}$. Since $T_{g}^{1}=\frac{1-P_{2}}{P_{2}}(D-\Delta)$ 


$$
\begin{aligned}
C_{g}{ }^{1} \equiv & W-R^{1}-T_{g}^{1}=W-R+\Delta-T_{g}^{1} \\
& =W-R+\left(1-P_{2}\right) D-P_{2} T_{g}-\left\{\left(1-P_{2}\right)\left(D-T_{g}\right)\right\}=W-R-T_{g}=C_{g} .
\end{aligned}
$$

We need to check if the non-negativity constraints are satisfied. First, consider $\Delta>0$, i.e. there is a positive subsidy. As we reduce this subsidy until it becomes zero, and the proceeds transferred to the UI, as above, we need to check if the ICL is still positive. But we know that $R^{1}>0$ from Proposition 8 which applies for any value of $r$, including $r^{1} .{ }^{58}$ Then, Proposition 7 guarantees that $D>0$.

For $\Delta<0$, it is easy to check that were $r^{1}$ to turn negative as we increase $\Delta$ to $\Delta=0$ it would imply that that the optimality condition (equation (34)) could not be satisfied, implying in turn that the putative allocation $\left\{r * R *, D *, T *, T_{g} *\right\}$ could have been improved upon, so that $\left\{r, R, D, T, T_{g}\right\}$ could not in fact have been the optimal UB package.

Proposition 12 implies than an optimal UB package with any financing scheme can be converted to another UB package where $\mathrm{UI}$ is financed out of taxes on wages and debt forgiveness can be financed by charging a premium on income-contingent loans. This result allows us to confine our analysis to the set of UB's with self-financing schemes in characterizing the optimal UB package.

\section{Effort}

In our model the UB program leads individuals to increase their reservation wage, encouraging search. Much of the literature on unemployment focuses on search effort, e. Higher $r$ reduces incentives to exert effort in search. Assume, for instance, that with effort e, we increase the probability of getting another good job the first period, i.e. $\mathrm{P}_{1}(\mathrm{e})$, with $\mathrm{P}_{1}{ }^{\prime}>0$, and

$$
\mathrm{V}=2 P_{1} \mathrm{U}(\mathrm{W}-\mathrm{T})+\left(1-P_{1}\right)\left[\int_{W_{R}}^{W}\left[2 U\left(w_{1}\right)\right] d F+F\left(W_{R}\right) V_{U}(R, D ; r)\right]-\rho e
$$

\footnotetext{
${ }^{58}$ That is, consider the value of $\Delta$ (short of the fully separate financing scheme) at which $\mathrm{R}$ goes to zero. Then, a perturbation of that allocation making $\mathrm{R}>0$ would be welfare-enhancing, contradicting the assumption that the original allocation was welfare-maximizing.
} 
where $\rho$ measures the disutility of a unit of effort. It follows that $\mathrm{de} / \mathrm{dr}<0$. We can then solve for the optimal $r$. It is the solution to:

$$
\left(1-P_{1}\right) F\left\{U^{\prime}\left(r^{o}\right)-U^{\prime}\left(W-T^{o}\right)\right\}=\frac{d V}{d T}\left[\frac{d T}{d W_{R}} \frac{d W_{R}}{d r}+\frac{d T}{d e} \frac{d e}{d r}\right]=\frac{U^{\prime \prime}\left(W-T^{o}\right) r}{2}\left\{\left(1-P_{1}\right) \mathrm{f} \frac{U^{\prime}(r)}{2 U^{\prime}\left(\mathrm{W}_{\mathrm{R}}\right)}-\frac{P_{1}^{\prime} F}{P_{1}^{2}}\right\}
$$

Because of the adverse effect on job effort, optimal unemployment insurance entails lower $r$ than in the absence of the effort effect. But the externality effect is still zero when $r=0$, i.e. it is still the case that it is always desirable to provide some unemployment insurance.

However, the effect on GDP is more ambiguous. The expression for GDP is now (ignoring the disutility of search) the same as earlier, but now it is a function of e, which in turn is a function of $r$ :

$$
\frac{d G}{d r}=\left(1-P_{1}\right) f\left(W_{R}\right)\left(\bar{W}-2 W_{R}\right) \frac{d W_{R}}{d r}+P_{1}^{\prime}(2 W-\widehat{G}) \frac{d e}{d r}
$$

There are two effects at play here: search incidence and effort. ${ }^{59}$ While the first effect is positive, the search effort term can make the net effect on GDP negative, even when $r$ is very small.

The presumption in much of the literature is that the GDP effect of unemployment insurance is unambiguously negative. However, if the search incidence effect is large enough, and the effort effect is small enough, there may in fact be an increase in GDP. As we have seen, the former depends, for instance, on properties of $\mathrm{F}$ while the latter on properties of $P_{1}(\mathrm{e})$.

Suppose, on the other hand, that effort affects the probability $P_{2}$ of getting a good job with wage $\mathrm{W}$ in the second period, i.e., $P_{2}=P(e)$, where $P^{\prime}>0$ and $P^{\prime \prime}<0$. Suppose there is an upper bound on the feasible level of effort, and $P^{\prime} \rightarrow 0$ as $e \rightarrow \bar{e}$. ${ }^{60}$ The optimal ICL $\left(R^{e}, D^{e}(\equiv\right.$

\footnotetext{
${ }^{59}$ More generally, search effort could shift the probability distribution of wage offers: $F(w ; e)$. Then there is an additional adverse effect on G: $2 \frac{d e}{d r} \int_{W_{R}}^{\bar{W}} w_{1} f_{e} d w$.

60 Similar results hold if there is no upper bound to e. All that matters is the limiting value of $Q(e)$ defined below.
} 
$\left.D\left(R^{e}\right)\right)$ can be solved by maximizing the expected utility $V_{U}(R, D ; r)$ for an unemployed worker:

(41) $V_{U}(R, D ; r)=U\left(C_{1}\right)+\operatorname{Max}_{e}\left[P(e) U\left(C_{g}\right)+(1-P(e)) U\left(C_{b}\right)-\rho e\right]$,

The choice of search effort $e^{*}$ is determined by the following condition:

$$
\frac{\partial V_{U}}{\partial e} \equiv \mathrm{E}\left(e^{*}, \mathrm{R}, \mathrm{D}\right)=P_{1}^{\prime}\left(e^{*}\right)\left[\mathrm{U}\left(C_{g}\right)-U\left(C_{b}\right)\right]-\rho=0,
$$

implying that the debt forgiveness lowers search effort. As before, the optimal ICL $\left(R^{e}, D(R)\right)$ can by first, maximizing D for given $R$, and then optimizing on $R$ (See Appendix A4 for derivations). We obtain

(44) $U_{1}^{\prime}-U_{g}^{\prime}-Q(e) D\left(R^{e}\right)\left(\frac{U_{g}^{\prime}}{P}\right)^{2}=0$

where $Q(e) \equiv-\frac{\left(P^{\prime}\right)^{3}}{\rho P^{\prime \prime}}(>0)$, where the superscript e denotes the value of the variable in the endogenous e environment, where the inequality (or the equality) in (43) holds when $D=R$ (or when $D<R$ ), and where we have made use of the finance constraint (24), where $\mathrm{P}_{2}$ is now endogenous. ${ }^{61}$

Conditions (43) and (44) imply that consumption smoothing (between $C_{1}$ and $C_{g}$ and between $C_{b}$ and $\left.C_{g}\right)$ are limited by concerns about adverse effects on effort $(Q(e)>0)$. If $\mathrm{Q}=0$, there is complete consumption smoothing. 62

\footnotetext{
${ }^{61}$ Since e depends just on $\mathrm{C}_{\mathrm{g}}$ and $\mathrm{C}_{\mathrm{b}}$, and since, at fixed e, we can obtain any optimal consumption allocation through the independent financing arrangement, we can do so with endogenous e.

${ }^{62} \mathrm{Q}=0$ when $\mathrm{P}^{\prime} \rightarrow 0$ (effort doesn't affect search outcomes) or $\mathrm{P}^{\prime \prime}$ is tending to (minus) infinity (search effort is unaffected by outcomes).

Consider a case where $\mathrm{P}$ is linear in $\mathrm{e}$ up to $\mathrm{e}^{*}$, and at $\mathrm{e}^{*}$ there is a kink in $\mathrm{P}(\mathrm{e})$, so that (at least for small changes in $r$ ) e will not change as $r$ changes. We are then (locally) in the model analyzed in earlier sections of this paper.
} 
From (43), despite costly and endogenous search effort, the critical properties of $D(R)$ remain intact: $D(R)>0$ for any $R>0$, while $D(R)=R$ when $\mathrm{R}$ (and hence $\mathrm{D}$ ) is small.

By the envelope theorem, the formula for the optimal value of $\left(r^{e}, T^{e}\right)$ is unchanged:

$$
\begin{aligned}
\left(1-P_{1}\right) F\left\{U^{\prime}\left(r^{e}\right)-U^{\prime}\left(W-T^{e}\right)\right\}= & \frac{d V}{d T} \frac{d T}{d V_{U}} \frac{d V_{U}}{d r}=\frac{d V}{d T}\left[\left.\frac{\partial T}{\partial V_{U}} \frac{\partial V_{U}}{\partial r}\right|_{e=e^{*}}+\frac{\partial T}{\partial V_{U}} \frac{\partial V_{U}}{\partial e} \frac{\partial e}{\partial r}\right] \\
& =\left(1-P_{1}\right) U^{\prime}\left(W-T^{e}\right) r^{e} f \frac{U^{\prime}\left(r^{e}+R^{e}\right)}{2 U^{\prime}\left(W_{R}^{e}\right)}
\end{aligned}
$$

The following Proposition clarifies how the optimal UB package is affected by the endogeneity of search.

\section{Proposition 13}

(i) $r^{e}>0, R^{e}>0$

(ii) Suppose that $P^{\prime}(e) \rightarrow 0$ faster than $\mathrm{P}^{\prime \prime} \rightarrow 0$ (while $P(e) \rightarrow \bar{P}(\leq 1)$ ), so that $Q \rightarrow 0$ as $e \rightarrow$

$\bar{e}$. Then $\left(r^{e}, R^{e}, D^{e}\right) \rightarrow\left(r^{*}, R^{*}, D^{*}\right)$ as $\rho \rightarrow 0 .{ }^{63}$

Proofs can be found in the Appendix A5. Proposition 13 (i) shows that it is still always desirable to provide UI and to introduce ICL despite the adverse effect on effort. Proposition 13(ii) shows that the optimal UB package approaches the one with exogenous search effort as $\rho$ goes to zero. Similarly, for sufficiently large $\rho$, e goes to zero. If we assume $P_{2}=P_{2}{ }^{*}$, the value of $P_{2}$ is assumed in earlier sections of the paper, all the results derived there continue to hold. While individuals could choose to exert more effort, given the costs (relative to the benefits) they choose not to do so.

\section{Risk aversion and intertemporal elasticity of substitution}

Buried in the seemingly innocuous assumption of the time additively separable expected utility function is, in fact, a strong assumption: in that model, the intertemporal elasticity of substitution is totally linked with the degree of risk aversion; more risk-averse individuals have a

${ }^{63}$ More precisely, we simply need $\mathrm{Q}(\mathrm{e}) \rightarrow 0$ as $e \rightarrow \bar{e}$. 
lower intertemporal elasticity. The two are, however, totally different concepts. In this section, we illustrate that by considering the limiting case of zero intertemporal elasticity with varying degrees of risk aversion.

In any state (life-course), $U=U\left\{\min \left\{C_{t}, C_{t+1}\right\}\right\}$. Expected utility is $E U$, where the expectation is taken over all life-courses. As before, one utility function is more risk averse than another if it can be obtained as a concave transform of the first. We refer to the degree of risk aversion, as before, by $\alpha$. It is easy to show that for an unemployed individual, without ICL, $U=$ $U\left\{\min \left\{r, w_{2}\right\}\right\}$, from which we can derive $w_{R}=w_{2}, r^{o}=w_{2}$, so long as the individual is risk

averse and $W-\frac{1-P_{1}}{2 P_{1}} F\left(w_{2}\right) w_{2} \geq w_{2}$. The degree of risk aversion or the shape of $F$ has no effect on the optimal unemployment insurance payment. That is driven by the low (zero) intertemporal elasticity of substitution.

With an ICL, there is an income-contingent loan that, together with $r$, brings consumption while unemployed up to $w_{2}$; but $R$ cannot be so large as to lower consumption in the good state (when the unemployed gets a good job) below $w_{2}$. That is, $W-R-\frac{\left(1-P_{2}\right) R}{P_{2}} \geq w_{2}$, or $R \leq$ $P_{2}\left(W-w_{2}\right)$. Moreover, we require $r+R \leq w_{2}$. Thus $r=\max \left\{0,\left(1+P_{2}\right) w_{2}-P_{2} W\right\}$, again unaffected by the degree of risk aversion. But, consistent with our earlier analysis, there is always some ICL and ICL lowers $r$. In this limiting case, it has no effect on consumption in the unemployed state.

The deeper exploration of the design of optimal UB systems in the more general case will have to be left to another occasion. ${ }^{64}$ Here, we simply note that the lower the intertemporal elasticity of substitution, the more important the potential role of ICL.

\section{Conclusion}

This paper has analyzed the design of optimal unemployment insurance systems, balancing out the marginal benefit of income smoothing with the marginal cost of the tax externality, and

${ }^{64} \mathrm{~A}$ popular way to separate risk aversion from the elasticity of intertemporal substitution is to use Epstein-Zin (1989) preferences. 
expanded the analysis of the design of unemployment programs to include income-contingent loans, showing how unemployment programs with ICL can always improve welfare as a result of better interstate and intertemporal smoothing while reducing search distortions. When search efficiency is increased, GDP may increase. We provide sufficient conditions under which UB programs increase GDP.

We have also analyzed factors determining the optimal design of an unemployment benefit program, the mix of $\mathrm{UI}$ and $\mathrm{ICL}$, and the financing the optimal UB package: In our simple model, we show it can be done by financing UI through a tax on those who haven't lost their jobs; and by financing debt forgiveness by an interest surcharge on those taking up the ICL loans. ${ }^{65}$

Our analysis ignores other key externalities and distortions associated with search. Perhaps most importantly, with a fixed number of jobs, more intensive search by one individual does not lead to an increase in GDP: One individual's success comes at the expense of that of others. More broadly, there are "congestion" externalities in search, leading typically to the market engaging in excessive search. ${ }^{66}$ The private benefit of search exceeds the social benefit, which, with a fixed number of jobs, could be zero. ${ }^{67}$

This externality reflects the most important limitation of this paper (and of much of the related literature): it focuses on the supply side of the economy. It analyses search and consumption distortions in an economy in which there is a job for everyone who wants one, if he could only find it. More search improves the quality of the job match.

\footnotetext{
${ }^{65}$ More generally, within a utilitarian framework like the one used here, a progressive unemployment tax imposed on lifetime income would be desirable. In most existing unemployment schemes, there is no attempt at interstate smoothing in the taxes imposed to finance unemployment benefits.

${ }^{66}$ The problem is analogous to fishing from a common pool, where it is well known that in the absence of government intervention of some form, there will be excessive fishing. For a more recent formalization entailing restocking of the pool, see Stiglitz (2014).

${ }^{67}$ In the absence of skill or preference matching. Implicitly such matching does occur in our model where individuals get a higher-paying job as a result of more search because of better matching. (Note that individuals care about the non-pecuniary attributes of a job, and so more search may lead to improved welfare even when wages or GDP do not increase.)

Landais et al (2018) focus their attention on this externality, affecting the overall tightness of the labor market. Marinescu (2017) identified the extent of this macroeconomic externality by showing that a $10 \%$ increase in UI benefit duration reduces job applications by $1 \%$ without affecting job vacancies.
} 
These demand-side effects are related to a second important set of externalities to which UI gives rise - macroeconomic externalities. ${ }^{68}$ In the presence of price rigidities and imperfect insurance, government intervention through UI can obviously increase societal welfare, in part by increasing aggregate demand. ${ }^{69}$ Indeed, the fact that unemployment programs act as automatic stabilizers means that there are social benefits associated with these programs that are not well-captured in the models presented here.

The market is not only inefficient in the search intensity of each individual, but also in the number and selection of individuals engaged in searching. There are two "selection" problems: ensuring that the individuals who do search are the right individuals; and matching individuals with jobs. These are problems that cannot be addressed within the context of models such as

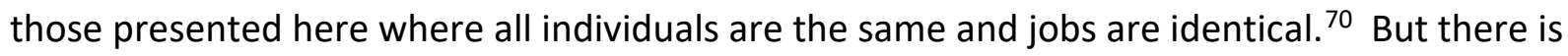
one interesting aspect of our proposed improvement in UB programs that may have some salience. ${ }^{71}$ One would like those who receive the least consumer surplus out of search to drop out of the search process. Investment in job search for young people is likely to be more valuable than for older individuals. Our model shows how UB raises reservation wages. Its effects are especially likely to be strong on liquidity constrained individuals - young people who have not been able to build up their precautionary savings balances. Thus, it is plausible that a well-designed UB program may change the mix of searchers towards those with a higher social benefit to search ${ }^{72}$. More generally, by expanding the set of instruments within the UB

\footnotetext{
68 Jeanne and Korinek (2018), Korinek (2018) Dávila and Korinek (2018) and Farhi and Werning (2016), the generalization to macroeconomics of the pecuniary externalities identified by Greenwald and Stiglitz $(1986,1988)$. The externalities analyzed by Farhi and Werning are more of the nature of the spillovers discussed in more traditional macroeconomics, and captured in the simple model by Neary and Stiglitz (1983).

${ }^{69} \mathrm{It}$ is easy to show that in these situations, Ricardian equivalence does not hold, so that UI benefits for generation $t$ financed by debt to be paid back, either by later generations or by the individual at some later time in his life, leads to an increase in aggregate demand. See Stiglitz (1988).

One could argue that these macroeconomic benefits could be obtained in other ways, e.g. checks to the poor, as during the pandemic; and the macroeconomic externalities (per dollar spent) might even by higher with appropriately targeted assistance.

${ }^{70}$ There is a large literature on job matching. In general, market equilibrium is inefficient. See, e.g. Stiglitz (1985), Arnott and Stiglitz (1985), Jovanovic (1982), and Hosios (1990).

${ }^{71}$ We are indebted to conversations with George Akerlof on this.

72 Or more precisely, towards those for whom there is a greater disparity between the net marginal social and private returns.
} 
program (to include possibly a range of income-contingent loans), one can enhance the ability to address the full range of moral hazard and adverse selection problems associated with ameliorating the consequences of unemployment.

There are search externalities other than the worker/worker externalities just discussed ${ }^{73}$. There is also a worker-firm externality. Most of the now-standard models focus on individual search behavior, not the broader labor flows, involving quits, fires, lay-offs, and search-bothon-the-job and after being fired or laid off. These are interdependent. The probability that an individual quits when a job is not to his liking (e.g. because of non-pecuniary aspects of the job including those associated with his interaction with his boss, which might not have been anticipated before he accepted the job) is greater if (at any level of overall unemployment) there are greater labor flows (Stiglitz, 1985). ${ }^{74}$ Because there will typically be some turnover costs borne by the firm, this higher quit rate imposes costs on firms; but higher labor flows confers a positive externality on other workers. ${ }^{75}$

In short, search is complex ${ }^{76}$ : "optimal" search entails specifying who searches and when, with a time profile of reservation wages; it is not just a matter of "effort," but as Marinescu and

\footnotetext{
${ }^{73}$ There is another set of effects, which have externality-like consequences, which we have ignored but which has received some attention in the literature and are potentially important. Search depends on savings, and savings is affected by the UB program. If savings is observable, in principle, UB programs should be made conditional upon it. If savings is unobservable, UB programs need to consider the indirect effects on search through savings. Kocherlakota (2004), Werning (2002) and Mitchell-Zhang (2008), show that the optimal benefit schedule will be affected by the presence of hidden savings. See also Michelacci-Ruffo (2015).

${ }^{74}$ These turnover costs/externalities were the subject of much of the earlier search literature. There are still other externalities. The extent of shirking (or a broader range of agency problems) will increase, because the cost of shirking decreases, making it desirable to increase wages, a cost to the firm, a benefit to workers. See Shapiro and Stiglitz (1984).

${ }^{75}$ When the firm wishes workers to leave, but would have to face severance pay should it fire the worker (including an increase in Ul experience rating), the higher quit rate may be a benefit (if the right people quit). In this case, though, there may be an adverse selection effect.

${ }^{76}$ Our more general model shows the dependence of many aspects of search behavior on very particular assumptions.

Recent literature, for instance, has investigated the relationship between $\mathrm{UI}$ and the duration of unemployment and wages workers receive when re-employed. Though we have not presented a multi-period version of our model, a natural implication is that better UB programs lead to a longer duration of unemployment (individuals have both a higher reservation wage and lower search effort). The standard presumption that higher UI would lead to a longer duration of unemployment has been confirmed by a number of studies (including Card-Levine (2000),
} 
Skandalis (2021) emphasize, where within the job market one concentrates one's effort. There are marked disparities between the social and private benefits of search, but while some individuals may search less and less intensively than in the first best world, others may search more; and while an increase in UI may discourage search in some circumstances and for some individuals, it may have the opposite effect on others. ${ }^{77}$

There are other important lessons of our analysis. The benchmark for analysis is often mistaken: much of the discussion begins with the presumption that the market level of search is optimal. This paper shows that to the contrary, with imperfect risk and capital markets, the market level of search is inefficient, and typically too low.

Our paper has emphasized that it is important to design unemployment benefit programs well. This paper has shown how that can be done, adding an important new tool to the policymakers' toolkit, income-contingent loans. Our discussion in these concluding remarks has highlighted

Meyer(1990)), but some recent studies (including Rothstein (2011)) report only a weak relationship between the two.

The empirical literature seems even more ambiguous about the effect of UI on wages. Ehrenberg-Oaxaca (1976) and Belzil (2001) found a weakly positive effect of the extension of UI benefits on reemployment wages. Similarly, Nekoei-Weber (2017) estimated a positive UI wage effect. On the other hand, Card et al (2007) and van OursVodopivec (2008) have not found any clear effect. Without commenting on the merits of the econometrics, our model may throw some light on why the relationship may be ambiguous: while individuals search in hope of a better wage, in our model if wage prospects the second period are the same as in the first period, observed wages at hiring actually decline over time because of the decrease in reservation wages. (Marinescu and Skandalis (2021) find that the target wage decreases over time.) If second-period wage prospects are enough better than those first period, observed wages may increase. More UI, in our basic model, leads to a higher reservation wage, which means higher average observed wages the first period and unchanged average wages for those re-employed.

Still more realistic variants of our model reinforce the ambiguities about the time profile of observed wages. Even as complicated a model as that which we have formulated here ignores important aspects of the real world. It may be, for instance, that higher (or more extended) UI initially leads to higher reservation wages (as suggested in our model), but that individuals are overly optimistic about future job prospects; eventually, however, they settle on a wage that is lower than they could have obtained earlier, either as they face liquidity constraints, even under extended UI, or as they learn that the markets value their skills less than they had initially thought.

77 We noted earlier the literature arguing that in the absence of government intervention, there may be "excessive search" (or at least more search than would occur in a first best equilibrium) even without the congestion effects we have identified, but as a result of liquidity effects. See Chetty (2008). This excessive search effect is consistent with the "added-worker" effect sometimes associated with increased unemployment rates, as families, worried that neither parent will get a job, have both search. See, e.g. Basu et al. 2002. 
too that because the magnitudes and even signs of the disparities between social and private returns to search differ across individuals and over the business cycle, better designed UB programs would differentiate among individuals and with the business cycle, providing, for instance, a further rationale for the automatic adjustment of UB in deep downturns, such as that of 2009 and 2020.

\section{Appendix A: Proofs and Derivations}

\section{Appendix A1: Proof that Assumption (A) is a Sufficient Condition for SOC for $\boldsymbol{r}^{o}$}

The FOC (22) for the optimal UI can be rewritten, dividing each side by $U^{\prime}(r) U^{\prime}(W-\mathrm{T})$ :

$$
K(r ; \alpha) \equiv \frac{1}{U^{\prime}(W-T)}-\frac{1}{U^{\prime}(r)}-r H \frac{1}{2 U^{\prime}\left(W_{R}\right) W_{R}}=0
$$

$$
\frac{d K(r ; \alpha)}{d r}\left(=\frac{\partial K(r ; \alpha)}{\partial r}+\frac{d K(r ; \alpha)}{d W_{R}} \frac{\partial W_{R}}{\partial r}\right)<0 \text { at } r=r^{o} \text { if } \frac{d K\left(r^{o} ; \alpha\right)}{d W_{R}}<0
$$

$\frac{d K\left(r^{o} ; \alpha\right)}{d \ln W_{R}}=\frac{d}{d \ln W_{R}}\left(\frac{1}{U^{\prime}\left(W-T^{o}\right)}\right)-\frac{r^{o} H}{2 U^{\prime}\left(W_{R}^{o}\right) W_{R}^{o}}\left[-W_{R}^{o} \frac{U^{\prime \prime}\left(W_{R}^{o}\right)}{U^{\prime}\left(W_{R}^{o}\right)}-1+\left.\frac{d \ln H}{d \ln W_{R}}\right|_{W_{R}=W_{R}^{o}}\right]$

$$
\begin{aligned}
& <-\frac{r^{o} H}{2 U^{\prime}\left(W_{R}^{o}\right) W_{R}^{o}}\left[-\frac{W_{R}^{o} U^{\prime \prime}\left(W_{R}^{o}\right)}{U^{\prime}\left(W_{R}^{o}\right)}-1+\left.\frac{d \ln H}{d \ln W_{R}}\right|_{W_{R}=W_{R}^{o}}\right] \quad\left(\text { because } \frac{d}{d W_{R}}\left(\frac{1}{U^{\prime}\left(W-T^{o}\right)}\right)<0\right) \\
& =-\frac{r^{o} H}{2 U^{\prime}\left(W_{R}^{o}\right) W_{R}^{o}}\left[\alpha\left(W_{R}^{o}\right)-1+\left.\frac{d \ln H}{d \ln W_{R}}\right|_{W_{R}=W_{R}^{o}}\right] \\
& <0 \text { if }\left.\frac{d \ln H}{d \ln W_{R}}\right|_{W_{R}=W_{R}^{o}}>1-\boldsymbol{\alpha}\left(W_{R}^{o}\right)
\end{aligned}
$$

\section{Appendix A2: Proof of Proposition 5}

(iii) $\frac{d r}{d P_{2}}<0$ and $\frac{d r}{d w_{2}}<0$

If (A) holds, $\frac{\partial K\left(r^{o} ; x\right)}{\partial W_{R}}<0$ by $\left(22^{\prime \prime}\right)$ so that $\frac{d K\left(r^{o} ; x\right)}{d x}=\frac{\partial K\left(r^{o} ; x\right)}{\partial W_{R}} \frac{\partial W_{R}}{\partial x}<0\left(x=P_{2}\right.$ or $\left.w_{2}\right)$ because $\frac{\partial W_{R}}{\partial x}>0$. Thus, $\frac{d r^{o}}{d x}=-\frac{\frac{d K(r ; x)}{d x}}{\frac{d K(r ; x)}{d r}}<0$. 
Alternatively, if $r^{o} \approx 0, \frac{d K\left(r^{o} ; \alpha\right)}{d W_{R}} \approx \frac{d}{d W_{R}}\left(\frac{1}{U^{\prime}\left(W-T^{o}\right)}\right)<0$.

(iv) $\frac{d r}{d \alpha}>0$

As $W-T^{o}>W_{R}^{o}$ and $W-T^{o}>r^{o}$, there are two possible cases, which depends on the magnitude of second period job opportunities and the value of $r$.

a) $W_{R}^{o}>r^{o}$

Without loss of generality we can assume $\frac{\partial U\left(W_{R}^{o} ; \alpha\right)}{\partial \alpha}=0$. Then, $\frac{\partial U^{\prime}\left(W-T^{o} ; \alpha\right)}{\partial \alpha}<0$ and $\frac{\partial U^{\prime}\left(r^{o} ; \alpha\right)}{\partial \alpha}>$

0 . As above, $\frac{\partial K\left(r^{o} ; \alpha\right)}{\partial W_{R}}<0$ if $(\mathrm{A})$ holds or if $r^{o}$ is small, so that $\frac{d K\left(r^{o} ; \alpha\right)}{d \alpha}=\frac{\partial K\left(r^{o} ; \alpha\right)}{\partial \alpha}+\frac{\partial K\left(r^{o} ; \alpha\right)}{\partial W_{R}} \frac{\partial W_{R}}{\partial \alpha}>$

0 , because $\frac{\partial K\left(r^{o} ; \alpha\right)}{\partial \alpha}>0$, and $\frac{\partial W_{R}}{\partial \alpha}<0$. Thus, $\frac{d r^{o}}{d \alpha}=-\frac{\frac{d K(r ; \alpha)}{d \alpha}}{\frac{d K(r ; \alpha)}{d r}}>0$ if $(\mathrm{A})$ holds or if $r^{o}$ is small.

b) $W_{R}^{o}<r^{o}$

Again, without loss of generality we can assume $\frac{\partial U\left(r^{o} ; \alpha\right)}{\partial \alpha}=0$. Then, $\frac{\partial U^{\prime}\left(W-T^{o} ; \alpha\right)}{\partial \alpha}<0$ and $\frac{\partial U^{\prime}\left(W_{R}^{o} ; \alpha\right)}{\partial \alpha}>0$. Then, the same argument (as above) can be applied to get the desired result.

How tight is $(A)$ ? To see this, note from $\left(22^{\prime \prime}\right)^{78}$

$$
\begin{aligned}
\frac{d K(r ; \alpha)}{d r}= & \frac{U^{\prime \prime}(r)}{\left(U^{\prime}(r)\right)^{2}}-\frac{H}{2 U^{\prime}\left(W_{R}\right) W_{R}}+\frac{U^{\prime}(r)}{2 U^{\prime}\left(W_{R}\right)} \frac{d}{d W_{R}}\left(\frac{1}{U^{\prime}\left(W-T^{o}\right)}\right) \\
& -\frac{r^{o} H}{2 W_{R} U^{\prime}\left(W_{R}\right)}\left[\alpha\left(W_{R}^{o}\right)-1+\left.\frac{d \ln H}{d \ln W_{R}}\right|_{W_{R}=W_{R}^{o}}\right] \frac{U^{\prime}(r)}{2 U^{\prime}\left(W_{R}\right) W_{R}}
\end{aligned}
$$

78 Using $\frac{d}{d W_{R}}\left(\frac{1}{U^{\prime}\left(W-T^{o}\right)}\right)=\frac{U^{\prime \prime}\left(W-T^{0}\right)}{\left(U^{\prime}\left(W-T^{o}\right)\right)^{2}} \frac{d T}{d W_{R}}=\frac{U^{\prime \prime}\left(W-T^{0}\right)}{\left(U^{\prime}\left(W-T^{o}\right)\right)^{2}} \frac{1-P_{1}}{2 P_{1}} r f<0$ 


$$
\begin{aligned}
=\frac{U^{\prime \prime}(r)}{\left(U^{\prime}(r)\right)^{2}}- & \frac{H}{2 U^{\prime}\left(W_{R}\right) W_{R}}+\frac{U^{\prime}(r)}{2 U^{\prime}\left(W_{R}\right)} \frac{U^{\prime \prime}\left(W-T^{0}\right)}{\left(U^{\prime}\left(W-T^{o}\right)\right)^{2}} \frac{1-P_{1}}{2 P_{1}} r f \\
& \quad-\frac{r^{o} H}{2 W_{R} U^{\prime}\left(W_{R}\right)}\left[\alpha\left(W_{R}^{o}\right)-1+\left.\frac{d \ln H}{d \ln W_{R}}\right|_{W_{R}=W_{R}^{o}}\right] \frac{U^{\prime}(r)}{2 U^{\prime}\left(W_{R}\right) W_{R}}
\end{aligned}
$$

The SOC can clearly be satisfied if $A$ is violated if $r$ is small and $\lim _{r \rightarrow 0} \frac{1}{U^{\prime}(r) r}=0$. But the SOC can still be satisfied if $A$ is violated even if $r$ is not small, in which case the comparative statics may flip sign.

\section{Appendix A3: Proof of Proposition 10}

(ii) We will prove the result by contradiction. Suppose that $r^{*}+R^{*} \leq r^{0}$. This implies that $W-R^{*}-\tau=r^{*}+R^{*} \leq r^{0}<W-T^{0}$. The first equality comes from $U_{1}^{\prime}=U_{g}^{\prime}$. The last inequality comes from Proposition 4. Since $C_{b}<$ or $=w_{2}$, depending on whether there is not or is complete debt forgiveness, $V_{U}^{0}>V_{U}^{*}$ and therefore $W_{R}^{0}>W_{R}^{*}$. Note that our supposition also implies $r^{0}>r^{*}$ which implies that $T^{0}>T^{*}$. Rewrite equation (34) as

$K\left(r, T, W_{R} ; R\right) \equiv \frac{1}{U^{\prime}(W-T)}-\frac{1}{U^{\prime}(r+R)}-\frac{H r}{2 U^{\prime}\left(W_{R}\right) W_{R}}$.

It follows that $K\left(r^{*}, T^{*}, W_{R}^{*} ; R^{*}\right)<K\left(r^{0}, T^{0}, W_{R}^{0} ; 0\right)=0$ if $\mathrm{A}$ is satisfied, so $\left\{r^{*}, R^{*}\right\}$ could not have been the optimal UB program with an ICL.

(iii) From (32) and (33) $r+R(r)=\frac{1}{2}(r+\bar{W})$ or $\frac{1}{2}(r+W)$. Substituting this into (38'), one can see that $K$ is a function of $r$ and $W_{R}$ or of $r, W_{R}$ and $P_{2} \cdot \frac{d K}{d r}=\frac{\partial K}{\partial r}+\frac{\partial K}{\partial W_{R}} \frac{\partial W_{R}}{\partial r}<0$ because $\frac{\partial K}{\partial W_{R}}<0$ by (A) while $\frac{\partial K}{\partial r}<0$ and $\frac{\partial W_{R}}{\partial r}>0$. Since $\frac{d K}{d P_{2}}=\frac{\partial K}{\partial W_{R}} \frac{\partial W_{R}}{\partial P_{2}}+\frac{\partial K}{\partial P_{2}}<0$ because $\frac{\partial K}{\partial W_{R}}<0$ by (A) while $\frac{\partial W_{R}}{\partial P_{2}}>0$ and $\frac{\partial K}{\partial P_{2}}<$ $0, \frac{d r^{*}}{d P_{2}}<0$. As $R(r)=\frac{\bar{W}-r}{2}$ or $\frac{W-r}{2}$ (by (32) and (33)), $\frac{d R^{*}}{d P_{2}}=\frac{\partial R(r)}{\partial P_{2}}+\frac{\partial R(r)}{\partial r} \frac{d r^{*}}{d P_{2}}>0$ because $\frac{\partial R(r)}{\partial P_{2}} \geq 0$, $\frac{\partial R(r)}{\partial r}<0$ while $\frac{d r^{*}}{d P_{2}}<0$. The same will be true for $w_{2}$.

(iv) $\frac{d K}{d \alpha}=\frac{\partial K}{\partial \alpha}+\frac{\partial K}{\partial W_{R}} \frac{\partial W_{R}}{\partial \alpha}+\frac{\partial K}{\partial R} \frac{\partial R}{\partial \alpha}$. From the proof of Proposition 5 (iv) (in Appendix 2 above), $\frac{\partial K}{\partial \alpha}>0$. $\frac{\partial K}{\partial W_{R}}<0$ by (A), and $\frac{\partial W_{R}}{\partial \alpha} \leq 0 . \frac{\partial K}{\partial R}<0$ by (38'), and $\frac{\partial R^{*}}{\partial \alpha}=0$ as, by (32-33), $R^{*}$ is determined for a given 
$\mathrm{r}$, regardless of the curvature of the/ utility function. Thus, $\frac{d r^{*}}{d \alpha}>0$. Also, $\frac{d R^{*}}{d \alpha}=\frac{\partial R^{*}}{\partial \alpha}+\frac{\partial R^{*}}{\partial r} \frac{d r}{d \alpha}<0$ because $\frac{\partial R^{*}}{\partial \alpha}=0$ and $\frac{\partial R^{*}}{\partial r}<0$ by $(32-33)$.

\section{Appendix A4: Derivation of Necessary Condition for $\boldsymbol{R}^{*}$ and $\mathbf{D} *$ with endogenous e}

Taking derivatives of (42) w.r.t D or R and w.r.t e, we have

(A5.1) $\frac{\partial e}{\partial D}=\frac{(P)^{2}}{\rho P^{\prime \prime}}\left[U_{b}^{\prime}+\frac{1-P}{P} U_{g}^{\prime}\right]<0, \frac{\partial e}{\partial R}=-\frac{\left(P^{\prime}\right)^{2}}{\rho P^{\prime \prime}}\left[U_{b}^{\prime}-U_{g}^{\prime}\right]>0$.

Then, differentiating $V_{U}$ using (41) and (A5.1):

$\frac{d V_{U}}{d D}=(1-P)\left[U_{b}^{\prime}-U_{g}^{\prime}\right]+\frac{P^{\prime}}{P} D^{e} U_{g}^{\prime} \frac{\partial e}{\partial D}=(1-P)\left[U_{b}^{\prime}-U_{g}^{\prime}-Q(e) D^{e}\left(\frac{U_{b}^{\prime}}{1-P}+\frac{U_{g}^{\prime}}{P}\right) \frac{U_{g}^{\prime}}{P}\right] \geq 0$.

Given that $D(R)$ is set as above, the necessary condition for the optimal loan $R^{*}$ can be derived from:

$\frac{d V_{U}}{d R}=\frac{\partial V_{U}}{\partial R}+\frac{d V_{U}}{d D} \frac{\partial D}{\partial R}=0$

where $\frac{\partial V_{U}}{\partial R}=U_{1}^{\prime}-\mathrm{P}(\mathrm{e}) U_{g}^{\prime}-(1-\mathrm{P}(\mathrm{e})) U_{b}^{\prime}+\frac{P^{\prime}}{P} D U_{g}^{\prime} \frac{\partial e}{\partial R}$. Substituting (A.5.1) in each of the two cases, when $D=R$, at the boundary, so $\frac{\partial D}{\partial R}=1$; and the interior solution, when $\frac{d V_{U}}{d D}=0$, we obtain (44).

\section{Appendix A5: Proof of Proposition 13}

i) From (44) and (45), $\left.\frac{d V}{d R}\right|_{R=0}>0$ and $\left.\frac{d V}{d r}\right|_{r=0}>0$, respectively, implying the desired results.

ii) As $\rho \rightarrow 0, e \rightarrow \bar{e}$, if $Q(e) \rightarrow 0$ as $P^{\prime} \rightarrow 0$, for a given R, D with endogenous effort approaches the value with exogenous effort (by (43)), and $U_{1}^{\prime} \rightarrow U_{g}^{\prime}$ by (44), implying that $R^{e} \rightarrow$ $R^{*}$, and thus that $D^{e} \rightarrow D^{*}$. It also follows from (45) that $r^{e} \rightarrow r^{*}$. 


\section{Appendix B: Alternative Formulation of Optimal UI with Wage Tax}

In the text, we assume that the taxes used to finance UI were paid only by those who receive the high wage (formal sector) jobs the first period. This greatly simplified the analysis, because it meant that an increase in $r$ increased $V_{U}$, increased $T$, lowering the utility of those employed at $\mathrm{W}$ the first period, with no feedback effect on the second period. The results are, however, unaffected by assuming the tax is paid by those employed the second period at W. We simply replace the equation describing the expected utility of an unemployed worker by

$$
V_{U}(r)=U(r)+P_{2} U(W-T)+\left(1-P_{2}\right) U\left(w_{2}\right)
$$

and the budget constraint by

(16') $T=X\left(W_{R}\right) r$,

where $X\left(W_{R}\right) \equiv \frac{\left(1-P_{1}\right) F\left(W_{R}\right)}{2 P_{1}+\left(1-P_{1}\right) F\left(W_{R}\right) P_{2}}$. Setting $\sigma \equiv P_{2} X$, the portion of UI tax paid by those who are re-employed at $\mathrm{W}$ and using (17), we have

(B.1) $\frac{d V_{U}}{d r}=U_{1}^{\prime}-\sigma U^{\prime}(W-T)\left(1+(1-\sigma) \frac{\mathrm{Hr}}{2 U^{\prime}\left(W_{R}^{o}\right) W_{R}} \frac{d V_{U}}{d r}\right)$

$$
=\left[U^{\prime}(r)-\sigma U^{\prime}(W-T)\right][1+Z]^{-1}
$$

where $\mathrm{Z} \equiv \sigma(1-\sigma) \frac{\mathrm{Hr}}{2 U^{\prime}\left(W_{R}^{o}\right) W_{R}} U^{\prime}(W-T)>0 .{ }^{79}$ Differentiating expected utility $\mathrm{V}$, we obtain for the first order condition defining $\left(r^{o}, T^{o}\right)$,

(B. 2) $\quad \frac{d V}{d r}=-2 P_{1} U_{o}^{\prime} \frac{d T}{d r}+\left(1-P_{1}\right) F\left(W_{R}\right) \frac{d V_{U}}{d r}=0$.

Rewriting (B.2) by using (17) and (B.1), we have the first-order condition for $r^{o}$ :

(B.3) $\Omega \equiv U^{\prime}\left(r^{o}\right)-U^{\prime}\left(W-T^{o}\right)\left\{1+(1-\sigma) \frac{H r^{o}}{2 U^{\prime}\left(W_{R}^{o}\right) W_{R}} U^{\prime}\left(r^{o}\right)\right\}=0$ ，

or

\footnotetext{
${ }^{79}$ The term $\mathrm{Z}$ reflects the fact that the marginal increase in $V_{U}$ of $\mathrm{UI} r$ is limited by the increase in tax $\mathrm{T}$ that has to be paid by the re-employed at $\mathrm{W}$ (consuming $(\mathrm{W}-\mathrm{T})$ ) (due to the resulting increase in $W_{R}$ ).
} 


$$
(1-\sigma)\left[U^{\prime}\left(r^{o}\right)-U^{\prime}\left(W-T^{o}\right)\left\{1+\frac{H r^{o}}{2 U^{\prime}\left(W_{R}^{o}\right) W_{R}} U^{\prime}\left(r^{o}\right)\right\}\right]+\sigma\left[U^{\prime}\left(r^{o}\right)-U^{\prime}\left(W-T^{o}\right)\right]=
$$

0.

When $\sigma$ is close to 1 (or 0 ), the optimal $\mathrm{UI}$ will be characterized almost by the unconstrained intertemporal smoothing (or almost by the constrained interstate smoothing as shown by Chetty-

Baily rule). If we assume, as a sufficient condition for $r^{o}$, that $\Omega_{W_{R}}<0$ (instead of (A)), it can be easily shown that all the results in Proposition 5 hold.

\section{$<$ References>}

Acemoglu, D., and R. Shimer (1999), "Efficient Unemployment Insurance," Journal of Political Economy, Vol. 107, No. 5, 893-924

Arnott, Richard and J. E. Stiglitz (1985), "Labor Turnover, Wage Structure \& Moral Hazard: The Inefficiency of Competitive Markets," Journal of Labor Economics, 3(4), October, pp. 434-462

(1988), "The Basic Analytics of Moral Hazard," Scandinavian Journal of Economics, 90 (3), pp. 383-413.

(1990), "The Welfare Economics of Moral Hazard," in Risk, Information and Insurance:

Essays in the Memory of Karl H. Borch, H. Louberge (ed.), Norwell: Kluwer Academic Publishers, pp. $91-122$

Arnott, R., B. Greenwald, and J.E. Stiglitz (1994), "Information and Economic Efficiency," Information Economics and Policy, 6(1), pp. 77-88

R. Arnott, A. Hosios, and J. E. Stiglitz (1988), "Implicit Contracts, Labor Mobility and Unemployment,"American Economic Review, 78(5), December 1988, pp. 1046-1066.

Arrow, K. J. (1963), "Uncertainty and the Welfare Economics of Medical Care," American Economic Review, 53(5), pp. 941-973

Baily, Martin N. (1978), "Some Aspects of Optimal Unemployment Insurance," Journal of Public Economics, 10 (December): 379-402.

K. Basu, Garance Genicot, and J. E. Stiglitz (2002), "Minimum Wage Laws and Unemployment Benefits, When Labor Supply is a Household Decision," Markets and Governments, K. Basu, P. Nayak, and R. B. Ray (eds.), in Oxford University Press, pp.38-59.

Card, David, and Philip Levine (2000), "Extended Benefits and the Duration of UI Spells: Evidence from the New Jersey Extended Benefit Program." Journal of Public Economics. Vol. 78:107-38. 
Card D, Chetty R and Weber A. (2007), "Cash-On-Hand and Competing Models of Intertemporal Behavior: New Evidence from the Labor Market," Quarterly Journal of Economics, 122(4);15111560.

R. Chetty (2006), "A general formula for the optimal level of social insurance," Journal of Public Economics $901879-1901$

R. Chetty (2008), "Moral Hazard vs. Liquidity, Optimal Unemployment Insurance," Journal of Political Economy, 116(2), 176-233

Dávila, E. \& Korinek, A. (2018), "Pecuniary Externalities in Economies with Financial Frictions," Review of Economic Studies, Oxford University Press, vol. 85(1), pages 352-395.

Diamond, P. and J. E. Stiglitz (1974), "Increases in Risk and in Risk Aversion," Journal of Economic Theory, 8(3), pp. 337-360.

Ehrenberg RG, Oaxaca RL. (1976), "Unemployment Insurance, Duration of Unemployment, and Subsequent Wage Gain," American Economic Review, 66(5); 754-766.

Epstein, Larry G. and Stanley Zin (1989). "Substitution, Risk Aversion, and the Temporal Behavior of Consumption and Asset Returns: A Theoretical Framework". Econometrica. 57 (4): 937-969.

Farhi, Emmanuel and Ivan Werning (2016), "A Theory of Macroprudential Policies in the Presence of Nominal Rigidities," Econometrica 84(5), pp. 1645-1704.

J. Flemming (1978), "Aspects of Optimal Unemployment Insurance: search, leisure, savings, and capital market imperfections," Journal of Public Economics, 10, pp. 403-25

Ganong, Peter, Fiona Greig, Max Liebeskind, Pascal Noel, Daniel M. Sullivan, and Joseph S. Vavra (2021a), "Spending and Job Search Impacts of Expanded Unemployment Benefits: Evidence from Administrative Micro Data." Working Paper.

Ganong, Peter, Fiona Greig, Max Liebeskind, Pascal Noel, Daniel M. Sullivan, and Joseph S. Vavra (2021b), "Micro and Macro Disincentive Effects of Expanded Unemployment Benefits." Working Paper.

Geanakoplos, J.D. and H.M. Polemarchaki (1986), "Existence, regularity and constrained suboptimality of competitive allocations when the asset structure is incomplete," in: W.P. Hell\&, R.M: Starr and D.A. Starrett, eds., Uncertainty, information and communication: Essays in honor of K.J. Arrow. Vol. 3 (Cambridge Universitv Press, New York) 65-95.

Greenwald, B. and J. E. Stiglitz (1986), "Externalities in Economies with Imperfect Information and Incomplete Markets," Quarterly Journal of Economics, Vol. 101, No. 2, pp. 229-264. 
(1988), "Pareto Inefficiency of Market Economies: Search and Efficiency Wage Models," American Economic Review, 78(2) pp. 351-355.

Gruber, Jonathan (1997), "The Consumption Smoothing Benefits of Unemployment Insurance." American Economic Review. 87 (1): 192-205.

Hansen, G, and A. Imohoroglu (1992), "The Role of Unemployment Insurance in an Economy with Liquidity Constraint and Moral Hazard," Journal of Political Economy, 118-142

H. Hopenhayn, J. Nicolini (1997), "Optimal Unemployment Insurance," Journal of Political Economy, 105, 312-438

Hosios, A. J. (1990), "On the efficiency of matching and related models of search and unemployment." The Review of Economic Studies, 57(2), 279-298.

Jappelli, Tullio and Luigi Pistaferri (2010), "The Consumption Response to Income Changes," NBER Working Paper Series 15739.

Jeanne, Olivier, and Anton Korinek (2018), "Managing credit booms and busts: A Pigouvian taxation approach." Journal of Monetary Economics (available online, 24 December).

Jovanovic, B. (1982), "Favorable selection with asymmetric information." The Quarterly Journal of Economics, 97(3), 535-539.

Korinek, Anton (2018), "Regulating capital flows to emerging markets: An

externality view." Journal of International Economics 111: 61-80.

C. Landais (2014), "Assessing the Welfare Effects of Unemployment Benefits Using the Regression Kink Design," American Economic Journal, 7(4): 243-278.

Landais, Camille, Pascal Michaillat, and Emmanuel Saez (2018), "A Macroeconomic Approach to Optimal Unemployment Insurance: Applications." American Economic Journal: Economic Policy, 10 (2): 182-216.

Marinescu, I (2017), "The General Equilibrium Impacts of Unemployment Insurance: Evidence from a Large Online Job Board," Journal of Public Economics 150, 14-29

Marinescu, loana, Skandalis, Daphné (2021), "Unemployment Insurance and Job Search Behavior.” The Quarterly Journal of Economics, Vol 136(2): 887-931,

Marinescu, loana Elena and Skandalis, Daphné and Zhao, Daniel (2020), "Job Search, Job Posting and Unemployment Insurance During the COVID-19 Crisis." Available at SSRN.

Meyer, Bruce (1990), "Unemployment Insurance and Unemployment Spells." Econometrica. Vol. 58(4):757-82.

Michelacci, Claudio and Hernán Ruffo (2015), "Optimal Life Cycle Unemployment Insurance." American Economic Review, 105(2): 816-59. 
Mitchell, Matthew and Yuzhe Zhang (2008), "Unemployment Insurance with Hidden Savings," Journal of Economic Theory, 145(6): 2078-2107.

Neary, J. Peter and Joseph E. Stiglitz (1983), "Toward a Reconstruction of Keynesian Economics: Expectations and Constrained Equilibria," Quarterly Journal of Economics, 98, pp. 199- 228.

Nekoei, A and A. Weber (2017), "Does Extending Unemployment Benefits Improve Job Quality?", American Economic Review, 107(2), 527-561.

Pavoni N. (2009), "Optimal unemployment insurance, with human capital depreciation, and duration dependence," International Economic Review 50(2): 323-362.

Petrosky-Nadeau, N. and Robert E. Valletta (2020), “Did the \$600 Unemployment Supplement Discourage Work?" FRBSF Economic Letter 2020-28.

Rogerson, William (1985), “Repeated Moral Hazard.” Econometrica. 53 (1): 69-76.

Rothschild, M. and J. E. Stiglitz (1970), “Increasing Risk: I. A Definition,” with M. Rothschild, Journal of Economic Theory, 2(3), pp. 225-243.

Rothschild, M. and J. E. Stiglitz (1971), “Increasing Risk: II. Its Economic Consequences," with M. Rothschild, Journal of Economic Theory, 5(1), March, pp. 66-84.

J. Rothstein (2011), "Unemployment Insurance and Job Search in the Great Recession," NBER Paper 17534.

S. Salop (1974), "Systematic Job Search and Unemployment," Review of Economic Studies, 40, pp. 191-201.

Salop, J. and S. Salop (1976), "Self-Selection and Turnover in the Labor Market" The Quarterly Journal of Economics, 90(4), pp. 619-627.

C. Shapiro and J. E. Stiglitz (1984), "Equilibrium Unemployment as a Worker Discipline Device,", American Economic Review, 74(3), June 1984, pp. 433-444.

Shavell, S, and L. Weiss (1979), "Optimal Payment of Unemployment-Insurance Benefits over Time." Journal of Political Economy. 87 (6): 1347-1362.

Shimer, R. and I. Werning (2008), "Liquidity and Insurance for the Unemployed," American Economic Review, 98(5).

J. E. Stiglitz (1974), "Alternative Theories of Wage Determination and Unemployment in L.D.C.'s: The Labor Turnover Model," Quarterly Journal of Economics, 88(2), May 1974, pp. 194-227.

J. E. Stiglitz (1985), “Equilibrium Wage Distributions," Economic Journal, 95(379), September 1985, pp. 595-61. 
J. E.Stiglitz (1988), "On the Relevance or Irrelevance of Public Financial Policy," in The Economics of Public Debt, Proceedings of the 1986 International Economics Association Meeting, London: Macmillan Press, pp. 4-76.

J. E. Stiglitz (2013), The Selected Works of Joseph E. Stiglitz, Volume II: Information and Economic Analysis: Applications to Capital, Labor, and Product Markets, Oxford: Oxford University Press, 2013.

J. E. Stiglitz (2014), "Intellectual Property Rights, the Pool of Knowledge, and Innovation," NBER working paper 20014.

J.E. Stiglitz, J. Yun (2005), "Integration of Unemployment Insurance with Retirement Insurance," Journal of Public Economics, 89, pp. 2037-67.

J.E. Stiglitz, J Yun (2013), “Optimal Provision of Loans and Insurances against Unemployment from a Lifetime Perspective," NBER Working Paper 19064.

Van Ours JC, Vodopivec M. (2008), “Does Reducing Unemployment Insurance Generosity Reduce Job Match Quality?" Journal of Public Economics, 92(3-4); 684-695.

Werning, Ivan (2002), “Optimal Unemployment Insurance with Unobservable Savings,” mimeo.

Stephen Zeldes (1989), "Consumption and Liquidity Constraints: An Empirical Investigation," Journal of Political Economy, 97(2):305-346. 
Period 1

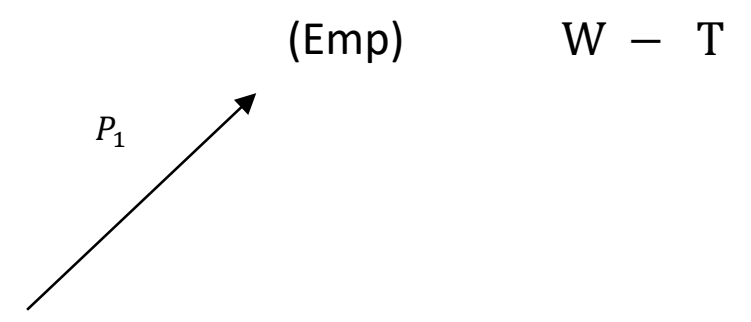

U

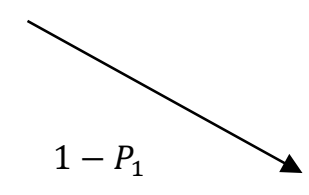

Period 2

$\mathrm{W}-\mathrm{T}$

\section{(Emp) $w_{1}$}

$\left(W_{R}\right)$

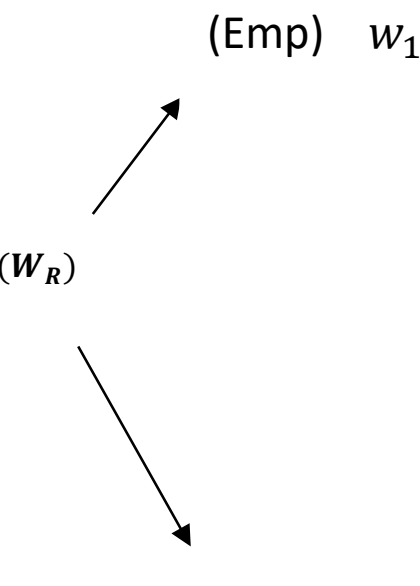

(Unemp) r + R (e)
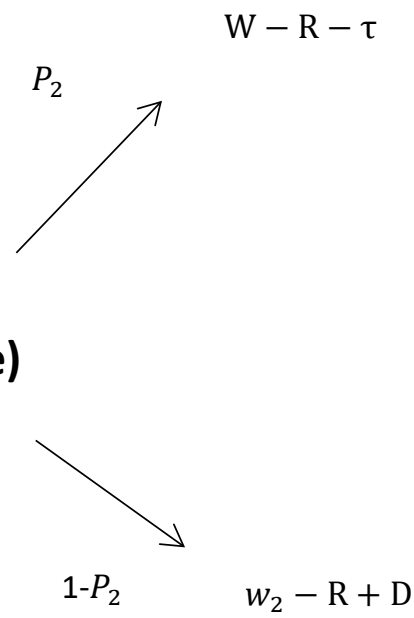

<Figure 1> Model 